NBER WORKING PAPER SERIES

\title{
IF DRUG TREATMENT WORKS SO WELL, WHY ARE SO MANY DRUG USERS IN PRISON?
}

\author{
Harold Pollack \\ Peter Reuter \\ Eric L. Sevigny \\ Working Paper 16731 \\ http://www.nber.org/papers/w16731
NATIONAL BUREAU OF ECONOMIC RESEARCH
1050 Massachusetts Avenue
Cambridge, MA 02138
January 2011

We thank Holly Nguyen for capable research assistance. We thank Jonathan Caulkins, Steven Raphael, and the conference organizers for excellent comments. The views expressed herein are those of the authors and do not necessarily reflect the views of the National Bureau of Economic Research.

NBER working papers are circulated for discussion and comment purposes. They have not been peerreviewed or been subject to the review by the NBER Board of Directors that accompanies official NBER publications.

(C) 2011 by Harold Pollack, Peter Reuter, and Eric L. Sevigny. All rights reserved. Short sections of text, not to exceed two paragraphs, may be quoted without explicit permission provided that full credit, including $\odot$ notice, is given to the source. 
If Drug Treatment Works So Well, Why Are So Many Drug Users in Prison?

Harold Pollack, Peter Reuter, and Eric L. Sevigny

NBER Working Paper No. 16731

January 2011

JEL No. G18

\section{ABSTRACT}

This paper examines the effectiveness of drug courts to reduce the size of the incarcerated drug-offending population using data from the Survey of Inmates in State Correctional Facilities and the Survey of Inmates in Local Jails. We find that very few of those entering state prison in 2004 or jail in 2002 would have been eligible for drug diversion through state drug courts. The policy implication is that drug courts and other diversion programs require substantial redesign if they are to contribute to a reduction in the incarcerated population.

Harold Pollack

University of Chicago

haroldp@uchicago.edu

Peter Reuter

University of Maryland

preuter@umd.edu
Eric L. Sevigny

1305 Greene St.

Department of Criminology and Criminal Justice University of South Carolina

Columbia, SC 29208

sevigny@mailbox.sc.edu 
Drug use, and drug sales, play central roles in the history of American crime. One cannot discuss crime in America in the 1970s without reference to the heroin epidemic nor in the 1980s and early 1990s without reference to powder and crack cocaine. The highly punitive regime in place now for drug offenders is largely a response to the association of these epidemics with crime waves.

Yet these drug epidemics unfolded a long time ago, with apparently low rates of initiation into drug dependence in recent years. From the vantage point of 2011, one might think that that these drugs no longer matter much, and that dependent drug use plays a smaller role in crime and criminal justice policy than it did ten or twenty years ago. In fact, however, data from many sources (some described below) indicate that those arrested or incarcerated within the American criminal justice system remain heavily involved in the consumption of illicit drugs.

There is abundant evidence that inducing criminal offenders to halt or reduce their substance use would reduce crime. Policymakers, researchers, and advocates have long argued that broader provision of substance abuse treatment could reduce the number of Americans behind bars.

In fact, however, a major component of the relentless growth in the U.S. incarcerated population over the last 35 years has been the rising number of people imprisoned for drug offenses, (Blumstein et al. 1999) a figure that rose from 42,000 in 1980 to 481,000 in 2002 (Caulkins and Chandler 2006). Most of this incarceration burden falls on people who were involved in supplying drugs, albeit sometimes in minor roles (Sevigny and Caulkins 2004). In addition, a large number of those incarcerated for both drug and nondrug offenses appear to satisfy screening criteria for drug use disorders. Many are dependent on cocaine, heroin, or 
methamphetamine; there is reasonable evidence that their drug use has a causal role in their criminality (MacCoun et al. 2003).

Substance abuse treatment provides a highly imperfect response to these problems. During any given treatment episode, the typical client is likely to continue some level of substance use. Relapse is the norm rather than the exception as a treatment outcome. Even so, at the individual level, there is compelling evidence that treatment markedly reduces both drug use and related criminal offending. Imperfect treatment works. This is just as well, since it describes the treatment we have.

An array of programs have developed over the last twenty years based on this evidence base, and more broadly on the well-documented premise that reducing drug use leads to large reductions in the individual offender's crime rate. The list of programs includes drug courts, other forms of diversion from the criminal justice system into treatment (e.g., Prop 36 in California), intensive supervision probation, and in-prison treatment. All these aim to reduce the extent of criminality among those who have already developed drug abuse or dependency by encouraging/coercing offenders into treatment. A substantial research literature shows that treatment does reduce both drug use and associated criminal activity. In addition to such programs, there is growing recent interest in "coerced abstinence” or "mandated desistance" interventions, whereby drug-involved offenders under criminal justice supervision in noncustodial settings (parole, probation, and pre-trial supervision) are subject to short, immediate, and graduated penalties for detected drug use (Kleiman 2009).

Despite this array of efforts, there has been no decline in the incarceration of drug users for either drug offenses or for other criminal activities. The number incarcerated for drug offenses has increased every year since 1980 (Caulkins and Chandler 2006). We show later in 
this paper that the number of state prisoners with drug problems also increased substantially from 1986 to 2004, extending analyses of CASA (2002) and Mumola and Karberg (2006), (Mumola and Karberg 2006; Belenko et al. 2002). We find strikingly similar patterns within the increasingly important population incarcerated in local jails.

Both of these findings are rather surprising, since the number of individuals with expensive illegal drug habits who are not incarcerated was estimated to have declined in the period 1988-2000, the most recent year for which a published estimate is available, (Office of National Drug Control Policy 2001) and there are some indicators that the decline may have continued. This would suggest that there are fewer sellers as well as fewer users to lock up.

Why has the U.S. achieved such limited success in getting criminal offenders to curtail their drug use? Put slightly differently, why is it so difficult to replicate at the population level the substantial reductions in drug use and criminal offending that treatment appears capable of achieving for individual offenders. Why aren't more offenders in treatment? And why have diversion programs such as California's Proposition 36 and drug courts proved relatively disappointing in achieving their stated goals?

We hypothesize that there are two main reasons for the continued large numbers of drug users flowing into, and remaining within, the correctional system:

First, eligibility criteria for diversion programs, particularly for drug courts, are restrictive. Although the various programs are effective and even cost-effective in serving the specific clients they recruit, they make only a small contribution at the population level. The diverted offenders are at low risk of going to prison or even jail (following sentencing, as opposed to pre-trial) in the absence of the drug court intervention. Given limited capacity and the 
relatively low-risk populations actually served, the currently-deployed model of drug courts is unlikely to notably reduce prison populations.

A second, related pattern also hinders the effectiveness of these interventions. There is a systematic mismatch between sentencing practices and actual criminal careers among druginvolved offenders. As individual criminally-active drug users get older, the system treats them increasingly harshly for each successive offense. They have longer criminal histories, longer records of unsuccessful treatment, and worse employment histories. Thus, not only are they less eligible for diversion programs, these offenders also receive longer sentences, increasing the share of the incarcerated population with drug problems.

The empirical contribution of this paper primarily concerns the first of these conjectures. In particular, we examine what share of those currently incarcerated would have been eligible for drug courts with the least restrictive entry criteria. We have not been able to find data that allows testing of the effect of the potentially lengthening criminal careers of dependent drug users.

To test the hypothesis about the ineffectiveness of drug courts to reduce the size of the incarcerated drug-offending population, we make use of the Survey of Inmates in State Correctional Facilities (SISCF) and the Survey of Inmates in Local Jails (SILJ), two Bureau of Justice Statistics (BJS) occasional surveys. Both provide self-reports on, inter alia, criminal activity and substance use from nationally representative samples of inmates; the Prison survey has been conducted six times between 1974 and 2004 (with federal inmates surveyed only in the 1997 and 2004 studies), while the Jail survey has been conducted six times between 1972 and 2002. We find that, indeed, very few of those entering state prison in 2004 or jail in 2002 would have been eligible for diversion through state courts. That this is true for local jails is much more 
surprising than the prison finding. This pattern provides a reminder that, even late in the incarceration boom, it is not so easy to get incarcerated, conditional on arrest.

There are two reasons for the findings about drug courts. First, many entering prison and jail (whether drug users or not) were on supervised release (parole or probation) at the time of their latest arrest, which automatically made them ineligible for most drug court interventions. Second, and more interestingly, most of those who were arrested do novo and who had drug use patterns making them potential clients for drug court, had long, relatively serious criminal records that would have made them ineligible under current conditions. Drug use itself may lead to more intense or longer criminal careers. Moreover, many of those dependent on expensive drugs (cocaine, crack, heroin and methamphetamine) became drug users a long time ago. These populations are aging, which is not true of nondrug-using criminal offenders. In effect, what we are seeing is two distinct trends in the incarcerated population, separated by drug use.

We also present three other policy-relevant descriptive findings:

First, it is useful to compare the number of dependent drug users entering treatment with the number entering prison. Both in 1986 and 2004, these figures are approximately comparable; the U.S. is locking up about as many drug addicts as it is treating, a troubling observation about the nation's drug policies.

Second there are indications that drug dependence is less prevalent among younger offenders than in cohorts that are twenty years older. Absent a new drug epidemic or a newly invigorated drug war, there is a predictable end in sight to the growth of drug-related prisoners.

Third, for drug using prisoners, the probability of a violent offense declines sharply with age after 35 . 
This last observation leads us to our principal policy suggestion, which needs further investigation. Diversion programs of all kinds require substantial redesign if they are to contribute to a reduction in the incarcerated population. Experienced drug users, who account for an increasing share of drug-related crime, are not attractive (or eligible) candidates for many current efforts. However if one is willing to take a very long-term social welfare perspective, it may be worth introducing courts specifically designed for the long-term user. Our finding that aging drug users commit relatively few violent crimes is helpful here. The risks associated with treatment-oriented community supervision of older offenders are therefore less than one likely encounters in younger drug-using cohorts.

The paper begins with three review sections. Section 1 describes the changing patterns of drug misuse in the U.S. over the last forty years, which is necessary to understand the challenge now facing the criminal justice system. Section 2 follows with a review of what is known about the effectiveness of drug treatment in reducing crime at the individual level. Section 3 briefly discusses interventions aimed at diverting drug-involved offenders from incarceration, such as drug courts, Prop 36 (the largest diversion program in operation, even though it is restricted to California alone), and coerced abstinence/mandated desistence in Hawaii. Section 4 presents our empirical analysis of the surveys of jail and state prison inmates, showing the limited potential impact of drug courts under current eligibility rules. Section 5 presents our conclusions.

\section{Background: The Changing Demography of Drug Misuse}

The dynamics of drug-related incarceration in the U.S. should be examined in light of broader societal trends in drug use and dependence over the last forty years. The characteristics 
of the drug using population, particularly those dependent on expensive drugs, has changed in ways that complicate the task of keeping criminally active drug users out of prison.

\section{Drug Epidemics}

The nation has experienced four major drug-specific epidemics in that period; heroin (ca. 1968-73), cocaine powder (ca. 1975-1985), crack cocaine (ca. 1982-1988), and methamphetamine (ca. 1990-2000). In an epidemic process, rates of initiation rise sharply as new and socially contagious users of a drug initiate friends and peers, a model first well developed by Hunt and Chambers (1976).

In the case of heroin, there is much evidence of a sudden elevation of initiation rates during the late 1960s and early 1970s, followed by a rapid incidence decline over the 1970s and 1980s (Kozel and Adams 1986; Rocheleau and Boyum 1994). A study of an early 1990s sample of street heroin users also found evidence of sharply peaked initiation rates in the late 1960s and early 1970s. For cocaine powder the rise was similarly rapid but decline was not so pronounced as with heroin (Everingham 1994). For crack cocaine the epidemic was still later, starting between about 1982 and 1986, depending on the city (Cork 1999). Caulkins et al. (2004) reported estimates of annual cocaine initiation using the NHSDA and a variety of methods; all show a peak in 1980 followed by a decline of two thirds in the next five years.

A new class of epidemiologic models has been developed by Caulkins and collaborators, (Caulkins et al. 2004; Caulkins 2007) which use diverse data to document the long trajectory of drug epidemics. After the peak, the initiation rate does not return to its original zero level but falls to a rate well below the peak. Under reasonable assumptions, the result is a flow of new users who do not fully replace those lost through desistance, death, or incarceration. Thus, the 
number of active users declines gradually over time. Moreover, the drug-using population ages with corresponding changes in the health, employment, and crime consequences of substance use.

Some evidence for this characterization can be seen in the changing characteristics of drug users in TEDS (the Treatment Episode Data System) which includes data on admissions to treatment programs that receive federal funds. We do not report changes in the National Household Survey on Drug Abuse/National Survey on Drug Use and Health (NHSDA/NSDUH) because these include so few dependent users. ${ }^{1}$

For TEDS we are able to compare the admission cohort of 1992 with that of 2006; these two years are the earliest and latest for which detailed data are available. By 1992 all but the methamphetamine epidemics had run their course but the cocaine and crack epidemics were relatively recent, so many of the users showing up for treatment were still young adults. Figure 1, computed using 1992 and 2006 TEDS data, displays changes in the age distribution of adult clients admitted into substance abuse treatment who reported cocaine-related disorders.

Insert Figure 1 here

In the 1992 data, $40 \%$ of clients were under the age of 30. By 2006, that figure had dropped to $26 \%$. The fraction of clients over the age of 40 rose from $15 \%$ to $47 \%$ over the same period. This was not the consequence of an epidemic of new use among older individuals; rather it represented the aging of those who were caught in the earlier epidemics.

We observed a more complex pattern within the population of admitted heroin users. As shown in Figure 2, the over-45 population displayed a similar pattern to that found in the population of cocaine users. Yet there was also a substantial population of admitted heroin users below the age of 30 . 
Insert Figure 2 here

The Drug Abuse Warning Network (DAWN) shows similar patterns of the aging of cocaine and heroin users appearing in emergency departments or as overdoses examined by medical examiners, through 2002.

The result of this epidemiology is that the demography of drug misuse changed substantially between the early 1990s and the 2000s. The average age of drug users increased markedly, with a more diverse set of primary drugs of abuse.

These data suggest that current service utilization reflects the long-term reverberation of specific epidemics of cocaine and heroin use in the United States. They also matter for the criminal justice system.

The only published estimates, distributed by the Office of National Drug Control Policy in 2001, of the numbers of dependent cocaine and heroin users cover the period 1988-2000 (Office of National Drug Control Policy 2001). Figure 3 presents these figures, which rely heavily on ADAM, showing a substantial decline, about one-third for each drug, over these 12 years. Both the data and the estimation methodology are weak, as indicated by the frequent adjustment in single year estimates in successive series published by the same research group over the period 1995-2000. For example, ONDCP's immediate preceding version of the estimates had shown an increase in heroin use in the early 1990s, followed by a rapid decline (Office of National Drug Control Policy 2000).

\section{Insert Figure 3 here}

Some of the decline in these estimates may represent the consequence of increased incarceration, since those in prison are not eligible for the ADAM sampling frame. Assume for the purposes of a rough calculation that the share of state prison inmates who would be classified 
as cocaine- or heroin-dependent prior to entering prison rose from 40\% of the 557,000 in 1988 to $50 \%$ of the $1,182,000$ in $2000^{2}$. That would have removed roughly 300,000 dependent cocaine and heroin users from the pool on which these estimates are based. Other trends may also account for some of the observed decline. For example, almost 200,000 injection drug users have died of HIV/AIDS.

Although these trends are important for many reasons, they account for less than onethird of the total decline (from 5.2 million in 1988 to 3.3 million in 2000). The best interpretation of the available data is that the number of individuals dependent on or abusing expensive drugs has been declining for a long period for a variety of reasons. The population of such users has aged, presumably reducing their involvement in violent crime.

\section{Drug Treatment}

Though the research has been critiqued by the National Research Council, (Manski et al. 2001), a substantial body of evidence indicates that substance abuse treatment is associated with large reductions in drug use and crime, especially during the period in which the individual drug user is in treatment. U.S. and British observational cohort studies document the strong association between treatment receipt and increased employment, improved health outcomes, and reduced criminal offending.

For example, Godfrey, Stewart, and Gossop (2004) reported two-year outcome data for 549 drug users enrolled in the British National Treatment Outcome Research Study (NTORS) (Godfrey et al. 2004). Expenditures on substance abuse treatment for these individuals totaled 7.3 million British pounds. Economic valuation of treatment-associated crime reduction totaled 27.4 million pounds for the same group. A 4-5 year follow-up indicated reductions in the 
frequency of heroin, street methadone, and benzodiazepines (Gossop et al. 2003). Crack cocaine and alcohol use were not significantly different after 4-5 years from the corresponding values at intake. Analyzing the same data, Gossop, Trakada, Stewart, and Witton (2005) found substantial reductions in acquisitive, drug selling, and violent crimes. Crime reductions were associated with reduced regular heroin use, simple aging, and living in stable housing.

Similar results were observed with U.S. data collected by the Drug Abuse Treatment Outcome Study (DATOS). Hubbard et al. (1997) reported that clients able to remain in long-term residential treatment for at least six months exhibited a 50\% reduction in illegal activity and a $10 \%$ increase in full-time employment. Koenig et al. (2005) and Ettner et al. (2006) observed similar patterns among treatment clients in Cuyahoga County, Ohio and California, respectively. Both of the latter papers reported strongly positive net benefits from treatment, with reductions in criminal offending accounting for the majority of the observed economic benefit associated with treatment intervention.

Prendergast and colleagues provide one widely-cited meta-analysis of these effects (Predergast et al. 2002). These authors examined results from 78 studies completed between 1965 and 1996. Twenty-five of these analyses also examined crime outcomes; 46 featured randomized study designs. These authors found that treatment was associated with reduced drug use (effect size $=0.30)$ and reduced crime (effect size $=0.13$ ).

In examining the impact of treatment on crime, reduced substance use appeared to be the critical mediating variable, with reduced substance use inducing lower rates of acquisitive crime. The average age of participating drug users was the only significant predictor of effect size, with treatment having a larger absolute impact in reducing crime among young adults (who are the most criminally active) than among older drug users. 
Some of the strongest findings for outpatient treatment arise in the arena of methadone maintenance therapy. For example, Amato et al. (2005) found that methadone maintenance therapy reduces criminality by as much as $60 \%$. The findings from a long-term cohort study of heroin users by Hser and colleagues finds similar results for a particularly recalcitrant heroinusing population (Hser et al. 2001).

Retention and treatment outcomes among opiate users appear sensitive to specific quality measures (D’Aunno and Pollack 2002). For example, methadone maintenance clients were markedly more likely to remain in treatment $(\mathrm{AOR}=1.72)$ when methadone doses exceeded 60 mg/day (Bao et al. 2009).

Many studies of opiate substitution therapy (OST) indicate a strong negative correlation between treatment engagement and retention on the one hand and criminal offending on the other. Campbell et al. (2007) examined arrest rates among Washington State opiate users. These authors found significantly reduced probability of arrest among treatment participants. Burdon et al. (2004) found quite similar results among California offenders participating in prison aftercare.

Given these strong relationships, both state and federal prisons sought to increase treatment provision to drug-involved offenders (Grella et al. 2007; Taxman et al. 2007). Most such services are low-intensity education and counseling services, which probably have a limited impact on criminal offending or drug use. More intensive residential modalities have also been implemented in prison, with greater evidence that treatment participants achieved better outcomes than comparison group members (Prendergast et al. 2004). However, because motivated individuals are more likely to enter and remain in treatment, many of the observed differences between treatment and comparison groups probably reflect favorable selection into treatment. 
Given the possibility—indeed the reality—of strong selection effects, randomized trials are especially important in evaluating the causal impact of treatment interventions. In one recent Australian study, Dolan et al. (2005) compared reincarceration, treatment mortality, and hepatitis C infection rates among opiate-dependent prison inmates randomly assigned to methadone maintenance and to a control group. Members of the treatment group displayed lower incidence of hepatitis C. Yet assignment to the treatment group appeared to provide little benefit in terms of long-term treatment retention.

In several recent papers, Gordon et al. (2008) and Kinlock and colleagues examined drug and crime outcomes of 211 heroin-dependent Baltimore prisoners who were randomly assigned to methadone maintenance or a control-group counseling intervention (Gordon et al. 2008; Kinlock et al. 2007; Kinlock et al. 2008; Kinlock et al. 2009). Offenders offered methadone maintenance shortly after release were significantly less likely to use heroin/cocaine or engage in criminal activity compared to those assigned to the control group.

A randomized trial by McMillan et al. (2008) yielded less favorable findings. Offering opiate-dependent inmates methadone maintenance within the jail setting appeared to confer little benefit absent an effective post-release intervention.

Outside the arena of opiate substitution therapy, the strongest evaluation results arise in establishing the benefits of therapeutic communities. For example, McCollister et al. (2005) conducted a five-year follow-up study examining the Amity in-prison therapeutic community and an accompanying Vista aftercare program for criminal offenders in southern California (McCollister et al. 2004).

The average cost of addiction treatment over the baseline and five-year follow-up period was $\$ 7,041$ for the intervention group and $\$ 1,731$ for the control group. However, the treatment 
group experienced 81 fewer incarceration days than was observed within the control group. This 13 percent reduction in incarceration more than offset the additional costs of the relatively intensive intervention. $^{3}$

Evaluations of outpatient drug-free interventions yield more mixed results. In the case of cocaine, a meta-analysis of research on interventions aimed at dependent users of a variety of drugs, few of whom were in methadone maintenance, found that those in treatment were about $20 \%$ more likely to have positive outcomes with respect to criminality than those who did not enter treatment (Prendergast and Burdon 2002). Even though most who enter treatment will relapse to drug use and/or fail to complete their treatment, it is still true that treatment can make a large difference in the lifetime drug use and criminality of a dependent user.

These large differences in criminal offending lead to correspondingly large impacts in cost-benefit analyses of substance abuse treatment. Substance abuse treatment is associated with many economic benefits. Yet crime reduction is consistently the largest single component of the economic benefit of treatment (Dismuke et al. 2004; Sindelar et al. 2004; French et al. 2002; McCollister and French 2003). Indeed the economic benefits of treatment-associated crime reductions are often larger than all other estimated benefits, combined.

The economic valuation of treatment-related crime reduction frequently exceeds, by itself, the entire cost of providing substance abuse treatment. In one prominent analysis of cocaine-dependent clients, Flynn et al. (1999) examined treatment clients' self-reported crime before and after treatment, finding that the economic value of an associated reduction in crime far exceeded the associated treatment costs.

Such findings are doubly striking because most studies in the empirical treatment literature understate the true social benefits associated with reduced crime. Most studies consider 
the tangible costs of crime-its direct costs to victims and to the health care and the criminal justice systems. The tangible cost approach provides a valuable lower bound to the benefits of crime reduction. However, such costs are a small fraction of the overall social costs of crime (Rajkumar and French 1997). Flynn et al. (1999) cite tangible costs of \$1,304 per burglary. By contrast, Cohen et al. (2004) obtain a per burglary cost estimate of $\$ 31,000$ using contingent valuation methodologies that capture a broader range of crime consequences and societal preferences (Cohen et al. 2004).

Basu et al. (2008) perform a (non-experimental) pre-post analysis of U.S. treatment data from the National Treatment Improvement and Evaluation Study (NTIES) that illustrates the importance of these valuation measures. Using conservative econometric specifications that were biased against a finding of treatment effectiveness, these authors show that the monetized value of treatment-related reductions in armed robbery more than offset the cost of the entire treatment intervention. This finding is especially striking when one considers that less than $7 \%$ of NTIES respondents reported committing an armed robbery in the year before treatment admission. Moreover, only 32\% of these robbery offenders reported ever being arrested for using a weapon or force to steal from a victim.

In terms of absolute numbers, substance abuse treatment providers serve a large and diverse population of substance users. As shown in Table 1, the number of individuals in drug treatment for cocaine or heroin abuse has risen slightly since 1997; e.g. TEDS data indicate admissions of 235,000 in 1997 for heroin, compared to 246,000 in 2005. Given that the estimated size of the population of dependent users has if anything shrunk, this indicates that the treatment fraction has increased. The figure for methamphetamine admissions almost tripled during the same period. 
Insert Table 1 here

\section{Drug Use and Crime}

The criminally active population continues to show high rates of drug misuse, another indication that treatment has, at the population level, failed to reduce the connection between crime and drug use.

For this population, ADAM provides the major source for insights into the connection between crime and drug use. ADAM includes data on drug use, both through interview and urinalysis, from a sample of arrestees in a number of counties around the country. Prior to 1998 we must rely on DUF (the Drug Use Forecasting) system, a statistically more primitive version of ADAM but one which turns out to provide data of comparable quality. When ADAM was operating most broadly, from 1998 to 2003, the data were collected in 35 counties. Data were not collected from 2003 to 2006, and since 2007 have been collected in only 10 counties (Office of National Drug Control Policy 2009). Thus ADAM provides an incomplete depiction of drug use among the arrested population nationally, particularly since 2003; city-level comparisons are more appropriate for comparing trends over time.

The most recent ADAM results (for 2008) show that use of cocaine, heroin, and methamphetamine continues to be common among arrestees in most cities. The percentage testing positive for cocaine varied between a high of $44 \%$ and a low of $17 \%$. Figures for heroin were lower, but were still as high as $29 \%$ for Chicago, twice as much as the next highest city.

For our purposes the more relevant comparisons are between 1986 and 2004, the era covered by the two inmate surveys we analyzed. DUF started collecting data in 1987 in just 21 cities (Wish and Gropper 1991). More complete and consistent data are available from 
Washington, DC, which has collected urinalysis on all adult arrestees since 1984 and on all juvenile arrestees since 1988. The adult data (Figure 4) show that the percentage of all arrestees testing positive for any drug excluding marijuana declined from $73 \%$ in 1987 to $49 \%$ in $1991{ }^{4}$ with a stable trend over the following 15 years.

\section{Insert Figure 4 here}

For juvenile arrestees (Figure 5) what is striking is how few have tested positive for any drug other than marijuana and PCP since the early 1990s; whereas in 1987 23\% tested positive for cocaine, that figure has hovered around 7\% since 1993.

\section{Insert Figure 5 here}

\section{Getting Offenders into Treatment}

As already noted, the insight that drug treatment could reduce both crime and the demands on the criminal justice system has animated policy for a long time, not just in the United States but in other countries. For example, the United Kingdom saw a near doubling of the population in treatment between 1998 and 2006, largely as a consequence of a large variety of criminal justice diversion programs (Reuter and Stevens 2007). We identify here just the major interventions.

Drug courts aim to use the coercive power of the criminal justice system, particularly the authority of a judge, to persuade drug-involved offenders to cease their drug use rather than face penalties for violating the terms of their release. Drug court clients are encouraged to seek treatment, and continued participation in treatment may be a condition for staying out of jail. The evaluation literature, though not technically strong, has generally found positive effects on recidivism, the usual outcome measure (Belenko and Peugh 2005; Wilson et al. 2006). 
Even though the drug court movement is almost 20 years old and over 2,300 separate programs have been created, (BJA Drug Court Clearinghouse Project 2009), a 2008 study estimated that only 55,000 drug involved defendants were processed in such courts in the middle of this decade; the same study estimated that over one million such defendants entered the criminal justice system each year (Bhati et al. 2008). Despite the rapid expansion of drug courts, the number of defendants who pass through such programs remain relatively low.

This small number of enrollees arises from several factors. Many jurisdictions lack administrative capacity to implement drug courts at-scale. Fifty-two percent of adult drug courts responding to one survey reported they cannot accept some eligible clients due to capacity constraints (Bhati et al. 2008). Bhati and colleagues estimate the current number of drug court "slots" at approximately 55,000. Given this constraint, there are strong administrative and political incentives for drug courts to cream-skim by serving relatively low-risk populations most likely to achieve successful outcomes rather than high-risk populations that would experience the greatest net reduction in criminal offending from drug court interventions.

Even if such administrative capacity were available, enrollment would remain sharply constrained by current eligibility restrictions. Despite the pervasiveness of the drug treatment court model, drug courts routinely exclude most of the drug-using offenders. A 2005 survey of adult drug courts found that "only $12 \%$ of drug courts accept clients with any prior violent convictions. Individuals facing a drug charge, even if the seller is drug-dependent, are excluded in $70 \%$ of courts for felony sales and $53 \%$ of courts for misdemeanor sales. Other charges that routinely lead to exclusion include property crimes commonly associated with drug use (theft, fraud, prostitution), and current domestic violence cases (only 20\% accept domestic violence cases) (Rossman et al. 2008). An earlier study conducted by the Government Accountability 
Office (1997) found that only 6\% of drug courts accept offenders whose current conviction included a violent offense.

A study of drug courts in six Washington state counties found substantial variation in eligibility requirements (Cox et al. 2001). In King County, for example, only defendants facing drug possession charges were eligible; whereas in Pierce County a long list of property crimes were also eligible. Similarly, Florida’s Dade County accepts offenders with mainly possession or purchase of a controlled substance charges. Marion County stipulates that eligible offenders must be charged with nonviolent drug offenses, with some drug sale and domestic violence cases considered (Florida Supreme Court Task Force on Treatment-Based Drug Courts 2004). Among the seven drug courts in New York City, three accept offenders facing drug sales charges; four do not. Only one court of the seven accepts defendants with nondrug felony charges.

Drug courts originally targeted first-time offenders who were arrested for possession or selling to support their habit. Some programs, however, are expanding to include repeat offenders and a few are accepting violent offenders (Porter 2001). Nevertheless, programs with flexible eligibility criteria are rare. Table 2 presents eligibility criteria for four drug courts in major jurisdictions.

\section{Insert Table 2 here}

More difficult to determine are the eligibility rules with respect to substance abuse. Bhati et al. (2008) report that "eligibility based on drug use severity is applied inconsistently—16\% of drug courts exclude those with a drug problem that is deemed too serious, while $48 \%$ reject arrestees whose problems are not severe enough. Almost 69\% exclude those with co-occurring disorders. Even among eligible participants, more than half of drug courts (52\%) report they 
cannot accept some clients who are eligible for participation due to capacity constraints” (p.8) (Bhati et al. 2008).

These eligibility rules seem likely to exclude most experienced users of cocaine, heroin, and methamphetamine. The few cohort studies of cocaine and heroin users (e.g. by Hser and colleagues) show that long-term users have accumulated long histories of convictions for property and violent crimes and that many_-perhaps most—have co-occurring disorders or are polydrug users (Hser et al. 2001; Hser 2007; Hser et al. 2007).

Estimating the potential effect of relaxing eligibility requirements is a major research challenge. Existing effectiveness findings reflect these tight eligibility requirements. Drug courts choose certain clients, and exclude more serious offenders, in the belief that defendants with longer and more serious criminal histories are more likely to have poor outcomes in drug courts. They may be correct; without evaluations of the effects with these other client groups, the research strategies for making projections are inherently speculative. We take this up in more detail in the paper's conclusion.

California's Proposition 36 provides the largest instance of diversion from the criminal justice system. Under Prop 36 (formally the Substance Abuse and Crime Prevention Act (SACPA)), first- or second-time drug possession arrestees with no record of violent offenses are subject to a drug abuse assessment to determine appropriate referral to a drug treatment program. Parolees or probationers who violate the drug conditions of their release or are arrested for drug possession are also eligible for Prop 36 sentencing to treatment or counseling. Participation in Prop 36 is contingent on pleading guilty to the possession charge. The majority of those arrested for simple possession of marijuana had more attractive legal options, which did not involve pleading guilty and thus did not enter Prop 36. Passed in 2000 by popular referendum, in its fifth 
year of operation (July 1, 2005 to June 30, 2006) it processed 52,000 individuals, (Urada et al. 2008) almost as many as the national drug court movement.

Given that Prop 36 is focused on individuals early in their criminal careers, it would appear to have little prospect of reducing prison populations. Yet it appears to have had a sizable effect. For example, Ehlers and Ziedenberg (2006) argue that Prop 36 accounted for a decline in the projected California prison population. Whereas the population had been projected increase from 162,000 to 180,000 between 2000 and 2005, the actual figure ended at only 164,000. Moreover, the rate of prison commitments for drug possession offenses in California fell from 80 per 100,000 on June 1, 2001 (date of implementation) to 57 per 100,000 four years later.

The state has funded a series of detailed evaluations of the effects of Prop 36 (Urada et al. 2008; University of California, Los Angeles Integrated Substance Abuse Programs 2007). A 42month follow-up of the first wave of Prop 36 arrestees found that the measure substantially reduced the levels of jail and prison incarceration of eligible Prop 36 offenders. The comparison was made between those deemed eligible for Prop 36 in the year before enactment and those who were eligible under Prop 36 in its first year. For state prisons, it appears that offenders who would have been eligible for sentencing under Prop 36 prior to its passage spent 100 days in state prison, whereas those who were sentenced under Prop 36 terms spent only about 60 days in prison. ${ }^{5}$ For county jails, the figures were similar; the average length of time in jail over 42 months fell from approximately 95 days to 65 days. ${ }^{6}$ The evaluations do not provide information on how much of that difference was accounted for by the initial incarceration spell, and how much was due to subsequences differences in reincarceration.

Almost three quarters of those who were processed under SACPA entered treatment. Substantial fractions drop out at various points in the process. The end result is that only one- 
third (one quarter of the initial intake) were discharged as having completed treatment. That figure is consistent with other studies of outcomes of treatment episodes resulting from criminal justice referrals. Given that Prop 36 clients are under much less threat of reincarceration than those entering through drug court referrals, for example, this is a surprising and encouraging finding, though it underscores the challenge of retaining criminally active populations in treatment interventions.

The Prop 36 population has some unexpected characteristics. For example, though this option is only available for first or second convictions on drug possession charges, it is a relatively old population with an average age of 34.8 years. Half have never entered treatment before. A substantial percentage have lengthy criminal records, even though this cannot include conviction for a violent offense.

Perhaps the inclusion of parolees among Prop 36 eligibles is an important source of the reduction in the prison and jail populations. However, only $13 \%$ of the clients in the most recent year of the evaluation entered from parole, and that figure had been as low as $8 \%$ in the first year of the program.

Over half of those sentenced under Prop 36 were charged with possession of methamphetamine, a drug associated with high levels of criminality. However, ADAM data show a low prevalence of methamphetamine in most U.S. cities (Office of National Drug Control Policy 2009); so the California reductions in incarceration may not generalize to other states.

On their face, the Proposition 36 findings are more encouraging than drug courts as a method for reducing drug-related incarceration at the population level. The California assessments consistently suggest that the use of noncriminal penalties has not produced increases in crime rates, either as a result of higher recidivism or of reduced deterrence. Though high-risk 
arrestees, primarily those with many prior arrests, fare less well than others, treatment oriented diversion aimed at non-marijuana possession arrestees may generate a meaningful reduction in total incarceration. There are however some concerns that the state sponsored evaluation, which is complex and not always clear, does not capture all the problems of implementation. For example, Hawken presents an analysis which finds that at the 30 month mark, arrests for all groups of Prop 36 arrestees (treatment completers, treatment drop-outs and treatment refusers) are higher than for the control group (Hawken 2009).

Coerced abstinence/mandatory desistence, a twenty year crusade by UCLA's Mark Kleiman, (Kleiman 2009; Kleiman 1997; Kleiman and Hawken 2008) is a program that takes advantage of simple findings from behavioral economics, psychology, and public policy. A large number of offenders are under community supervision at any one time, whether it be pretrial release, probation, or parole. Because they have been arrested or convicted, the government can subject these individuals to random drug tests and indeed does from time to time.

Coerced abstinence involves making sanctions certain, immediate, and relatively mild rather than (as is normally the case) random, delayed, and severe. Such interventions have not received widespread evaluation. The small number of existing studies have found that such programs have the predicted effects on recidivism (Harrell et al. 1998). So far, there have been no efforts to implement them on a large scale.

Recently, Hawaii's Opportunity Probation with Enforcement (HOPE) program has implemented the approach for the entire probation population. The results of a random assignment evaluation (Kleiman and Hawken 2008; Hawken and Kleiman 2009 have been very promising. Very few of those enrolled in the program fail more than twice and the recidivism rates have been dramatically lower than for the probation population previously. For example, 
only $21 \%$ of HOPE subjects were rearrested in the 12 month evaluation window, compared to 46\% amongst those on routine probation conditions (Hawken and Kleiman 2009).

These results and a clear articulation of the theory underlying the model by Mark Kleiman and others have given this intervention a great deal of political and professional prominence. HOPE-like experiments are being launched in a number of states. It offers the prospect of a large scale intervention that could be implemented relatively rapidly and without requiring the development of a new expertise in the probation community.

However, for those interested in promoting drug treatment as a major intervention to reduce the incarcerated population, it is striking that coerced abstinence does not necessarily involve treatment. Probation officers want their clients to desist from drug use, and this program gives them the tools to motivate and monitor abstinence. Many drug-involved offenders do not satisfy screening criteria for actual dependence. It is unclear that many of the successful clients entered drug treatment programs or that these individuals needed such services. The adverse consequences of a failed urine test have been enough to generate abstinence. Whether abstinence will continue post-supervision is an open question but in making a judgment about the utility of coerced abstinence, it is important to note that relapse is the common experience post-treatment.

The HOPE evaluation involved experienced offenders at risk of jail or prison.

Probationers assigned to HOPE were significantly less likely to produce positive drug tests or to be arrested over a 12-month study period. These offenders spent about one-half as many days in prison on revocations or new convictions. (See Table 3 below, reproduced from Hawken and Kleiman (2009)).

Insert Table 3 here

If HOPE were implemented on a wide scale, it might cut prison time substantially. 


\section{Incarceration and Drug Courts}

This section presents a new analysis of data on the incarcerated population, including both state prisons and local jails. First, we show that offenders with drug use problems continue to be a large share of those in jail and prison, and that recent entering cohorts of drug-using inmates are considerably older on average than late-1980s cohorts. Second we assess whether under the usual eligibility rules, an expansion of drug courts could substantially reduce the numbers of drug users locked up.

\section{Data and Analytic Framework}

We analyzed two waves of data each from the Survey of Inmates in State Correctional Facilities (SISCF) and the Survey of Inmates in Local Jails (SILJ), comparing changes in the standing local jail and state prison populations from the latter part of the 1980s to the early part of the 2000s. Specifically, the prison data are drawn from the 1986 and 2004 waves of the SISCF, and the jail data are drawn from the 1989 and 2002 waves of the SILJ. For the prison population, our analyses focus only on state inmates since the federal inmate survey was only added in 1997. Moreover, federal prisons account for fewer than $10 \%$ of all those incarcerated on any given day.

In both surveys, all data, including key indicators on prior offenses and on substance use, are based on inmate self-report. There is a substantial literature on such self-reporting in correctional settings both for criminal involvement (Horney and Marshall 1992) and substance use (Farabee and Fredlund 1996); this research suggests that the self-report methodology is a valuable data collection approach that provides an acceptable level of accuracy for both domains. 
The nationally representative inmate surveys employ a stratified two-stage sampling design, first selecting facilities and then inmates within the selected facilities. Total response rates across the four surveys ranged between $84 \%$ and $92 \%$. As shown in Table 4, the late 1980 s prison and jail surveys completed interviews with more than 19,000 inmates, generalizing to a standing incarcerated population of roughly 846,000. In comparison, the early 2000s prison and jail surveys completed interviews with more than 21,000 inmates, generalizing to a standing incarcerated population of about 1.86 million.

\section{Insert Table 4 here}

For purposes of our analyses, we focus on the past-year admission cohort of convicted inmates. Prior cross-period analyses of the inmate surveys (Mumola and Karberg 2006; Belenko et al. 2002) have made comparisons for the entire incarcerated populations. Since many inmates at each survey were incarcerated long before the survey itself, indeed were potential participants in an earlier wave, comparisons of the total stock population do not describe well the changing dynamics of incarceration. Thus we identify in each case an admission cohort of newly incarcerated offenders consisting of those inmates who entered prison or jail in the twelve months preceding the date of their interview. ${ }^{7}$ The resulting sample sizes and reference populations used for the present study are also presented in Table 4. All analyses were performed using Stata 11.0, with reported estimates weighted to account for the complex survey design.

\section{Measuring Drug Misuse}

We examined changes among inmate populations in the problematic use of heroin, cocaine, and methamphetamine. For each substance, we operationalized drug abuse as selfreported daily or near-daily use in the month prior to arrest. We also defined "cocaine” to 
include both powder and crack cocaine, and "methamphetamine" to include the more general class of amphetamines. ${ }^{8}$ Other possible indicators were less valid measures of drug abuse (e.g., any drug use in the month prior to arrest, intoxication at the time of the offense) or were entirely incommensurate across survey years (e.g., substance abuse and/or dependence).

\section{Results}

Drug Misuse among the Newly Incarcerated

Our first finding is that frequent drug use continues to be prevalent among recent entering inmate cohorts. Indeed, the percentage of newly incarcerated prison and jail inmates who reported daily or near-daily use of any of the three drugs increased by one-quarter and one-fifth, respectively, between the 1980s and the 2000s. In absolute numbers, this amounts to an overall increase of roughly 129,000 convicted, drug-using offenders entering prison or jail. Of note, this increase appears to be exclusively driven by the rise in methamphetamine use, as the share of heroin and cocaine users declined slightly to moderately across the two periods.

Insert Table 5 here

The Changing Age-by-Drug Distributions of the Newly Incarcerated

To capture the changing age profiles of drug-involved offenders, we compared the age distributions of newly-incarcerated drug-using inmates for the 1986 and 2004 prison surveys and the 1989 and 2002 jail surveys. Again, by newly incarcerated, we mean admitted to prison within the past year; and by drug abuse, we mean daily or near-daily use in the month prior to arrest. Figures 6-8 compare the age group distributions (in five-year increments) for cocaine, heroin, and methamphetamine, respectively. 
As shown in Figure 6, the cocaine-using cohorts aged considerably between the 1980s and 2000s. Reflecting a seven-year increase in the median age from 27 to 34, just $12.1 \%$ of newly-incarcerated cocaine-abusing prison inmates were 35 or older in 1986 compared to $47.3 \%$ in 2004. Among entering jail inmates, similar increases in the median age (27 to 36) and proportion of those 35 or older (17.0\% to 56.4\%) were found between 1989 and 2002.

Insert Figure 6 here

As shown in Figure 7, we found sizable but relatively smaller increases in population aging across the heroin-using cohorts, with equivalent four-year increases in the median ages of both newly-incarcerated prison (30 to 34) and jail (32 to 36) inmates. Examining the age distributions, we found that the percentage of newly-incarcerated heroin-abusing prison inmates who were 35 or older increased from roughly one-quarter to one-half (25.6\% to $48.7 \%$ ) between 1986 and 2004. A comparable percentage point increase (from 38.6\% to 57.2\%) in those 35 or older occurred among the heroin-abusing jail cohort. Of note, however, there was considerable parity across all survey years in the proportion of young (i.e., under 25) heroin abusers.

\section{Insert Figure 7 here}

For methamphetamine abusers, the median age rose from 26 to 30 among entering prison inmates and from 28 to 31 among entering jail inmates. In the late 1980s, just $8.0 \%$ and $11.0 \%$ of newly-incarcerated methamphetamine-abusing prison and jail inmates, respectively, were 35 or older (see Figure 8). By the 2000s, one-third or more of incoming methamphetamine-abusing prison (32.9\%) and jail (36.0\%) inmates exceeded this age.

Insert Figure 8 here

The remainder of the inmate cohorts-i.e. new entrants who did not report daily or neardaily use of any of the three expensive drugs in the month before arrest-showed much smaller 
aging patterns across survey years (see Figure 9). Median ages for entering cohorts of prison and jail inmates rose 3 and 2 years, respectively. In addition, unlike the drug-abusing inmates, the age distributions of the two non drug-abusing cohorts were virtually similar across time.

Insert Figure 9 here

The shifting age distribution of drug-involved offenders is especially important given the declining age profile of violent offenses in this population. The probability that offenders will satisfy criteria that disqualify them from diversion programs increases with age, even as the probability of violent offending declines.

The implications of these age patterns are shown below in Figure 10. Roughly one in four entering inmates below the age of 25 were sentenced for a violent offense, a percentage that steadily declined with age. Yet older offenders were markedly more likely to be labeled habitual offenders or to face sentencing enhancements that would exclude them from typical drug diversion programs. ${ }^{9}$

Insert Figure 10 here

\section{Drug Court Calculations}

In addition to examining age distributions, we examined the proportion of incoming prisoners with problematic drug use who would be eligible for drug court diversion.

We classified inmates—-first with the entering cohort and then with the entire incarcerated population—by characteristics that affect eligibility for drug courts. In Table 6, those characteristics that frequently disqualify the individual for drug court are italicized; those that make individuals likely candidates are in plain text.

Insert Tables 6 and 7 here 
As shown in Table 6, virtually all newly-incarcerated inmates are likely to be deemed ineligible for drug court intervention. Results are even sharper within the entire (not just the newly-incarcerated) population of drug-involved state prison inmates, as shown in Table 7. Authors' calculations indicate that more than $85 \%$ have current or past sentences for a serious felony or a gun violation. Non-incident inmates are twice as likely as incident inmates to be serving current sentences for violent offenses.

This pattern illustrates a point that arises in many contexts from unemployment to welfare reform. The stock population of incarcerated offenders are a "length-biased" sample. Compared with new entrants to prison in a given year, incarcerated offenders are more likely to be long-term offenders in the midst of long incarceration spells, and are more likely to satisfy other criteria of serious offending. As in the case of welfare cash assistance (Ellwood 1989), new entrants to prison/TANF are a distinct population from those who are long term prisoners/welfare recipients. Thus, programs that significantly affect the flow of new prison entrants may have a much more modest impact on the stock of incarcerated prisoners. We return to this point in the Conclusions section.

The patterns in Table 7 illustrate the central challenge in reducing the prison population through drug courts and other diversion programs. Problematic drug use was common among state prison inmates. The 2004 prison sample included almost 300,000 convicted prison inmates who had used cocaine, heroin, or amphetamine in the month prior to their admission to prison. More than $90 \%$ of these drug-involved inmates satisfied screening criteria for abuse or dependence. For the 2002 jail inmates, about 94,000 (of the 448,000 convicted inmates) used heroin, cocaine, or methamphetamine in the month prior to their admission. Similarly, more than $90 \%$ met criteria for substance abuse or dependence in the year prior to arrest. Thus a rough 
estimate is that in 2004 (projecting no change in the jail figure between 2002 and 2004) the number of drug dependent individuals entering jail and prison as convicted offenders was approximately 400,000.

To put these numbers into perspective, we compared our descriptive statistics with the 2005 Treatment Episode Data System (TEDS), an administrative data set that captures at least $80 \%$ of all known treatment admissions in the United States in 2004. TEDS data yield 680,775 treatment admissions for which cocaine, amphetamine, or heroin was the primary substance of misuse. The incarcerated drug-dependent populations in prisons and jails rival the substance abuse treatment system in the size of the drug-using population receiving services on any given day.

Yet only a small minority of inmates are likely to be eligible for drug courts or similar interventions. Among newly-incarcerated inmates, approximately one-fifth were under a current sentence for minor (that is, non-trafficking) drug offenses - the archetypal offense promoted as suitable for drug court intervention. An even smaller fraction were incarcerated for such crimes and had no current or prior record for disqualifying offenses. Minor drug offenders account for an even smaller fraction of the overall state prison population.

If one broadens the universe from minor drug crimes to include other offenses, diversion programs would have a slightly larger population to draw from. Approximately one-fifth of inmates reported no history or current sentences for serious felonies. ${ }^{10}$

Perhaps our most surprising descriptive findings concerned inmates in local jails. Based on our 2002 data, a very small fraction of sentenced jail inmates would be eligible for drug courts based on the eligibility criteria cited above. 
Prior criminal history factors exclude the largest share of offenders with current drug problems from drug court eligibility. More than 70 percent of heroin, cocaine, and methamphetamine users would be drug court-ineligible on the basis of being under criminal justice supervision at the time of arrest or of being a habitual offender. Virtually none of these inmates would be eligible for drug courts that applied every common exclusionary criterion. Setting aside important considerations of program capacity, this suggests that relaxing eligibility criteria, especially for offenders with active or long criminal histories, would expand the pool of criminal offenders eligible for drug court and related interventions.

\section{Conclusions}

We began this paper by noting that diverting drug-involved offenders from the criminal justice system, in particular getting them into treatment rather than jail or prison, has long been a major concern of the criminal justice system. The drug court movement has been a prominent and important innovation, almost universally praised by policy makers at every level of the criminal justice system. Other innovations, such as Proposition 36 in California and intensive supervision probation in various jurisdictions have pursued the same goal.

Notwithstanding that, we have documented that the numbers of drug-involved individuals in the U.S. state prison and local jail systems have risen substantially in the last twenty years, both in absolute numbers and as a percentage of the total. When we confine comparisons to those entering the prison system or jails de novo (our incident cohort) during the 1980s and after the year 2000, we see evidence that the entering drug-involved inmates are aging for the three drugs (cocaine, heroin and methamphetamine) in contrast to a much slighter increase in the age of those not involved with drugs. 
Prior studies, in particularly Bhati et al. (2008), have shown that drug courts have made little difference to the criminal justice system because they handle such small numbers of criminal defendants. Our paper adds to these findings with the observation that drug courts, as currently structured, have little potential to make a difference to incarceration totals because so few of those entering jail or prison would meet the eligibility requirements of the current courts.

This importantly reflects the observed aging of the populations involved with the three drugs we examined. A large share of drug-involved offenders entering correctional facilities have accumulated long criminal careers that make them unattractive clients for the drug court movement. It is especially discouraging that this statement applies to inmates in local jails, as well as state prisons.

Ironically, the aging of the drug using offenders has another consequence. They are now much less likely to be convicted of a new violent offense, the principal public concern about criminal offenders under community supervision. There has been growing interest in the time to “redemption” for those with a criminal history, i.e. the number of years after an arrest or conviction at which an individual is no longer much more likely to commit a new offense than someone who has never been arrested/convicted (Blumstein and Nakamura 2009). The policy question for drug courts is whether it is possible that a more careful analysis of the criminal careers of long-term drug users will allow the selection of some candidates for diversion programs with acceptable risks of committing a serious crime while under the supervision of a drug court or intensive probation.

Our results suggest other potential insights for policy. Reducing prison populations by diverting drug-involved offenders before incarceration seems more difficult than one might suspect. If diversion is unexpectedly difficult at the front end, other strategies may prove more 
effective. Greater attention and focus on the drug problems of recently-released offenders, parolees, and probationers seems especially fruitful.

The results of Proposition 36 are intriguing. Though it is a well known innovation, we are unaware of any study that has examined its potential to reduce prison and jail populations if taken up nationally.

Mandated desistence programs such as the Hawaii HOPE program yield impressive early results. These seem especially promising for individuals who abuse alcohol or illicit substances, but who may not be dependent or who use substances for which available substance abuse treatment appears relatively ineffective.

For opiate-dependent offenders, strengthening the immediate linkages into post-release opioid maintenance treatment also appears promising. Similar linkages of drug-involved offenders into long-term residential treatment and therapeutic communities also appear to be associated with reduced rates of subsequent reoffending.

Finally, more effective treatment interventions for young drug users who are not under criminal justice supervision appears especially promising. Young men receiving substance abuse treatment services display strikingly higher rates of criminal offending, particularly violent offending, than do others involved in the treatment system. Some of these young men present to the treatment system under implicit or explicit pressure from the criminal justice system. Others seek services for other reasons.

Although young adults are often more difficult treatment clients and may display poor outcomes by traditional clinical criteria, focusing resources on this key population is likely to yield high dividends for crime control and prevention policy. 


\section{Endnotes}

${ }^{1}$ For example, in 2000, self-reported prevalences among NHSDA respondents imply that 1.2 million individuals had used cocaine in the previous month. By comparison, more broad-based estimates that included ADAM estimated a total of approximately 2 million that met the more stringent requirement of having used the drug more than 8 times in the 30 days prior to the interview. The differential for heroin was similar (Boyum and Reuter, 2005; p.18).

${ }^{2}$ The calculation is done only for state prisoners because (a) jail inmates serve short terms on average and are eligible within the year for rearrest and ADAM inclusion, and (b) federal inmates include a large fraction of nonresident offenders.

${ }^{3}$ Analysis that accounted for the social benefits of averted crime would likely find even more striking benefits of substance abuse treatment.

${ }^{4}$ Most of the late 1980s decline was the result of an abrupt reduction in the percentage testing positive for PCP, a drug that has been much more prevalent in Washington than any other city, even after the decline. ${ }^{5}$ This is based on dividing the estimated state prison costs provided in the report by the reported daily cost of a prison stay.

${ }^{6}$ The report does not offer a figure for the cost of a day in jail; these calculations assume that it is $\$ 62.50$, a figure cited by Ehlers and Zeidenberg (2006). Ehlers and Ziedenberg estimate the number of jail days saved per client per year to be approximately 12, which is roughly consistent with the 30 days estimated in the above calculation.

${ }^{7}$ Because the SILJ does not ask unconvicted jail detainees pertinent questions on offender substance use and other key indicators, our analyses are by necessity restricted to convicted inmates.

${ }^{8}$ We note, however, that the 1986 SISCF and 1989 SILJ collected data only on the use of “amphetamine,” whereas the 2004 SISCF and 2002 SILJ asked separate questions about "amphetamine” and “methamphetamine.” Similarly, the 1986 SISCF employed a single measure of “cocaine,” the 1989 SILJ a single measure of "cocaine or crack," and the 2004 SISCF and 2002 SILJ separate measures of 
“crack” and "cocaine other than crack.” Accordingly, the earlier surveys likely provide more conservative estimates of cocaine and methamphetamine use as we have defined it.

${ }^{9}$ Current violent offense measures any current conviction offense, not just a controlling violent offense. Habitual offender enhancement is defined as receiving a sentence enhancement for a second- or thirdstrike offense.

${ }^{10}$ Homicide, manslaughter, kidnapping, armed robbery, unarmed robbery, burglary, aggravated assault, assault on a police officer, arson, blackmail, extortion, sex crimes, drug trafficking, other violent crimes. 


\section{References}

Amato, Laura, Marina Davoli, Carlo A. Perucci, Marica Ferri, Fabrizio Faggiano, and Richard P. Mattick. 2005. “An Overview of Systematic Reviews of the Effectiveness of Opiate Maintenance Therapies: Available Evidence to Inform Clinical Practice and Research.” Journal of Substance Abuse Treatment 28(4): 321-9.

Bao, Yan-ping, Zhi-min Liu, David Epstein, Cun Du, Jie Shi, and Lin Lu. 2009. “A MetaAnalysis of Retention in Methadone Maintenance by Dose and Dosing Strategy.” American Journal of Drug and Alcohol Abuse 35(1): 28-33.

Basu, Anirban, A. David Paltiel, and Harold A. Pollack. 2008. "Social Costs of Robbery and the Cost-effectiveness of Substance Abuse Treatment.” Health Economics 17(8): 927-46.

Belenko, Steven, Jordan Peugh, Daniel Mendez, Courtney Petersen, Jeffrey Lin, and Jennie Hauser. 2002. Trends in Substance Abuse and Treatment Needs Among Inmates. National Criminal Justice Reference Service. New York: National Center on Addiction and Substance Abuse at Columbia University.

Belenko, Steven, and Jordon Peugh. 2005. “Estimating Drug Treatment Needs among State Prison Inmates.” Drug and Alcohol Dependence 77(3): 269-81. 
Bhati, Avinash Singh, John K. Roman, and Aaron Chalfin. 2008. To Treat or Not to Treat:

Evidence on the Prospects of Expanding Treatment to Drug-Involved Offenders. Washington, D.C.: Urban Institute.

BJA Drug Court Clearinghouse Project. 2009. Summary of Drug Court Activity by State and County, July 14, 2009. Washington, D.C.: BJA Drug Court Clearinghouse Project at American University.

Blumstein, Alfred, and Allen J. Beck. 1999. "Population Growth in U.S. Prisons, 1980-1996.” In Crime and Justice: A Review of the Research, Prisons (volume 26), edited by Michael Tonry and Joan Petersilia, 17-61. Chicago: University of Chicago Press.

Blumstein, Alfred, and Kiminori Nakamura. 2009. "Redemption in the Presence of Widespread Criminal Background Checks.” Criminology 47(2): 327-59.

Burdon, William M., Nena P. Messina, and Michael L. Prendergast. 2004. “The California Treatment Expansion Initiative: Aftercare Participation, Recidivism, and Predictors of Outcomes.” Prison Journal 84(1): 61-80.

Campbell, Kevin M., Dennis Deck, and Antoinette Krupski. 2007. “Impact of Substance Abuse Treatment on Arrests among Opiate Users in Washington State.” American Journal on Addictions 16(6): 510-20. 
Caulkins, Jonathan P. 2007. “The Need for Dynamic Drug Policy.” Addiction 102(1): 4-7.

Caulkins, Jonathan P., Doris A. Behrens, Claudia Knoll, Gernot Tragler, and Doris Zuba. 2004. "Markov Chain Modeling of Initiation and Demand: The Case of the U.S. Cocaine Epidemic." Health Care Management Science 7(4): 319-29.

Caulkins, Jonathan P., and Sara Chandler. 2006. “Long-Run Trends in Incarceration of Drug Offenders in the United States.” Crime and Delinquency 52(4): 619-41.

Cohen, Mark A., Roland T. Rust, Sara Steen, and Simon T. Tidd. 2004. "Willingness-to-Pay for Crime Control Programs.” Criminology 42(1): 89-110.

Cork, Daniel. 1999. “Examining Space-time Interaction in City-level Homicide Data: Crack Markets and the Diffusion of Guns among Youth.” Journal of Quantitative Criminology 15(4): 379-406.

Cox, Gary, Linda Brown, Charles Morgan, and Michelle Hansten. 2001. NW HIDTA / DASA Washington State Drug Court Evaluation Project: Final Report. July 13. Seattle: Alcohol and Drug Abuse Institute, University of Washington.

D'Aunno, Thomas, and Harold A. Pollack. 2002. "Changes in Methadone Treatment Practices: Results from a National Panel Study, 1988-2000.” Journal of the American Medical Association 288(7): 850-6. 
Dismuke, Clara E., Michael T. French, Helena J. Salomé, Mark A. Foss, Chris K. Scott, and Michael L. Dennis. 2004. “Out of Touch or On the Money: Do the Clinical Objectives of Addiction Treatment Coincide with Economic Evaluation Results?” Journal of Substance Abuse Treatment 27(3): 253-63.

Dolan, Kate A., James Shearer, Bethany White, Jialun Zhou, John Kaldor, and Alex D. Wodak. 2005. "Four-Year Follow-Up of Imprisoned Male Heroin Users and Methadone Treatment: Mortality, Re-incarceration and Hepatitis C Infection.” Addiction 100(6): 820-8.

Ehlers, Scott, and Jason Ziedenberg. 2006. Proposition 36: Five Years Later. Washington, D.C.: Justice Policy Institute.

Ellwood, David T. 1989. Poor Support: Poverty in the American Family. New York: Basic Books.

Ettner, Susan L., David Huang, Elizabeth Evans, Danielle Rose Ash, Mary Hardy, Mickel Jourabchi, and Yih-Ing Hser. 2006. "Benefit-Cost in the California Treatment Outcome Project: Does Substance Abuse Treatment ‘Pay for Itself’?” Health Services Research 41(1): 192-213.

Everingham, Susan S., and C. Peter Rydell. 1994. Modeling the Demand for Cocaine. Santa Monica, CA: RAND Corporation. 
Farabee, David, and Eric Fredlund. 1996. "Self-reported Drug Use among Recently Admitted Jail Inmates: Estimating Prevalence and Treatment Needs.” Substance Use \& Misuse 31(4): 42335.

Florida Supreme Court Task Force on Treatment-Based Drug Courts. 2004. Florida's Adult Drug Court: Recommended Practice. Tallahassee, FL: Florida Supreme Court Task Force. Accessed May 25, 2010. http://www.flcourts.org/gen_public/family/bin/dcreport.pdf.

Flynn, Patrick M., Patricia L. Kristiansen, James V. Porto, and Robert L. Hubbard. 1999. “Costs and Benefits of Treatment for Cocaine Addiction in DATOS.” Drug and Alcohol Dependence 57(2): 167-74.

French, Michael T., Helena J. Salomé, Jody L. Sindelar, and A. Thomas McLellan. 2002. "Benefit-cost Analysis of Addiction Treatment: Methodological Guidelines and Empirical Application using the DATCAP and ASI.” Health Services Research 37(2): 433-55.

Godfrey, Christine, Duncan Stewart, and Michael Gossop. 2004. "Economic Analysis of Costs and Consequences of the Treatment of Drug Misuse: 2-year Outcome Data from the National Treatment Outcome Research Study (NTORS).” Addiction 99(6): 697-707.

Gordon, Michael S., Timothy W. Kinlock, Robert P. Schwartz, and Kevin E. O'Grady. 2008. “A Randomized Clinical Trial of Methadone Maintenance for Prisoners: Findings at 6 Months Postrelease.” Addiction 103(8): 1333-42. 
Gossop, Michael, John Marsden, Duncan Stewart, and Tara Kidd. 2003. “The National Treatment Outcome Research Study (NTORS): 4-5 Year Follow-up Results.” Addiction 98(3): 291-303.

Gossop, Michael, Katia Trakada, Duncan Stewart, and John Witton. 2005. "Reductions in Criminal Convictions after Addiction Treatment: 5-year Follow-up.” Drug and Alcohol Dependence 79(3): 295-302.

Grella, Christine E., Lisa Greenwell, Michael Prendergast, David Farabee, Elizabeth Hall, Jerome Cartier, and William Burdon. 2007. “Organizational Characteristics of Drug Abuse Treatment Programs for Offenders.” Journal of Substance Abuse Treatment 32(3): 291-300.

Harrell, Adele, Shannon Cavanagh, and John Roman. 1998. Findings from the Evaluation of the D.C. Superior Court Drug Intervention Program. Final Report. Washington, D.C.: Urban Institute.

Hawken, A. 2009. "Managing Drug-involved Offenders: Comparing Diversion Programs and Hawaii's HOPE Probation.” June 15. Washington D.C.: Office of National Drug Control Policy.

Hawken, Angela, and Mark Kleiman. 2009. "Managing Drug Involved Probationers with Swift and Certain Sanctions: Evaluating Hawaii's HOPE.” Washington, D.C.: National Institute of Justice. 
Horney, Julie, and Ineke Haen Marshall. 1992. “An Experimental Comparison of Two SelfReport Methods for Measuring Lambda.” Journal of Research in Crime and Delinquency 29(1): $102-21$.

Hser, Yih-Ing, Valerie Hoffman, Christine E. Grella, and M. Douglas Anglin. 2001. “A 33-year Follow-up of Narcotics Addicts.” Archives of General Psychiatry 58(5): 503-8.

Hser, Yih-Ing. 2007. “Predicting Long-term Stable Recovery from Heroin Addiction: Findings from a 33-year Follow-up Study.” Journal of Addictive Diseases 26(1): 51-60.

Hser, Yih-Ing, David Huang, Chih-Ping Chou, and M. Douglas Anglin. 2007. “Trajectories of Heroin Addiction: Growth Mixture Modeling Results Based on a 33-year Follow-up Study.” Evaluation Review 31(6): 548-63.

Hubbard, Robert L., S. Gail Craddock, Patrick M. Flynn, Jill Anderson, and Rose M. Etheridge. 1997. “Overview of 1-year Follow-up Outcomes in the Drug Abuse Treatment Outcome Study (DATOS).” Psychology of Addictive Behaviors 11(4): 261-78.

Hunt, L.G., and C.D. Chambers. 1976. The Heroin Epidemic: A Study of Heroin Use in the U.S., 1965-1975 (Part II). New York: Spectrum. 
Kinlock, Timothy W., Michael S. Gordon, Robert P. Schwartz, Kevin O'Grady, Terrence T. Fitzgerald, and Monique Wilson. 2007. “A Randomized Clinical Trial of Methadone Maintenance for Prisoners: Results at 1-month Post-release.” Drug and Alcohol Dependence 91(2-3): 220-7.

Kinlock, Timothy W., Michael S. Gordon, Robert P. Schwartz, and Kevin O'Grady. 2008. “A Study of Methadone Maintenance for Male Prisoners: 3-month Post-release Outcomes." Criminal Justice and Behavior 35(1): 34-47.

Kinlock, Timothy W., Michael S. Gordon, Robert P. Schwartz, Terrence T. Fitzgerald, and Kevin E. O'Grady. 2009. “A Randomized Clinical Trial of Methadone Maintenance for Prisoners: Results at 12 months Postrelease.” Journal of Substance Abuse Treatment 37(3): 27785.

Kleiman, Mark A.R. 1997. “Coerced Abstinence: A Neopaternalistic Drug Policy Initiative.” In The New Paternalism: Supervisory Approaches to Poverty, edited by Lawrence M. Mead, 182218. Washington, D.C.: Brookings Institution Press.

Kleiman, Mark A.R. 2009. When Brute Force Fails: How to Have Less Crime and Less Punishment. Princeton, NJ: Princeton University Press.

Kleiman, Mark A.R., and Angela Hawken. 2008. “Fixing the Parole System.” Issues in Science and Technology 24(4): 45-. 
Koenig, Lane, Jonathan M. Siegel, Henrick Harwood, Jawaria Gilani, Ying-Jun Chen, Peter Leahy, and Richard Stephens. 2005. “Economic Benefits of Substance Abuse Treatment: Findings from Cuyahoga County, Ohio.” Journal of Substance Abuse Treatment 28(2) supp. 1: S41-S50.

Kozel, N.J., and E.H. Adams. 1986. "Epidemiology of Drug Abuse: An Overview.” Science 234(4779): 970-4.

MacCoun, Robert, Beau Kilmer, and Peter Reuter. 2003. "Research on Drugs-Crime Linkages: The Next Generation." In Toward a Drugs and Crime Research Agenda for the 21st Century, edited by Henry H. Brownstein and Christine Crossland, 65-95. Washington, D.C.: National Institute of Justice.

Manski, Charles F., John V. Pepper, and Carol V. Petrie, editors. 2001. Informing America's Policy on Illegal Drugs: What We Don't Know Keeps Hurting Us. Washington, D.C.: National Academy Press.

McCollister, Kathryn E., and Michael T. French. 2003. "The Relative Contribution of Outcome Domains in the Total Economic Benefit of Addiction Interventions: A Review of First Findings.” Addiction 98(12): 1647-59. 
McCollister, Kathryn E., Michael T. French, Michael L. Prendergast, Elizabeth Hall, and Stan Sacks. 2004. "Long-term Cost Effectiveness of Addiction Treatment for Criminal Offenders." Justice Quarterly 21(3): 659-79.

Mumola, Christopher J., and Jennifer C. Karberg. 2006. "Drug Use and Dependence: State and Federal Prisoners, 2004.” Special Report, NCJ 213530. Washington, D.C.: Bureau of Justice Statistics.

Office of National Drug Control Policy. 2000. "What America's Users Spend on Illicit Drugs 1988-1998.” Washington, D.C.: White House Office of National Drug Control Policy.

Office of National Drug Control Policy. 2001. "What America's Users Spend on Illicit Drugs 1988-2000.” Washington, D.C.: White House Office of National Drug Control Policy.

Office of National Drug Control Policy. 2009. ADAM II: 2008 Annual Report. Washington, D.C.: White House Office of National Drug Control Policy.

Porter, Rachel. 2001. Treatment Alternatives in the Criminal Court: A Process Evaluation of the Bronx County Drug Court. New York: Vera Institute of Justice.

Prendergast, Michael L., and William M. Burdon. 2002. "Integrated Systems of Care for Substance-Abusing Offenders.” In Treatment of Drug Offenders: Policies and Issues, edited by Carl G. Leukefeld, Frank Tims, and David Farabee, 111-26. New York: Springer. 
Prendergast, Michael L., Deborah Podus, Eunice Chang, and Darren Urada. 2002. “The Effectiveness of Drug Abuse Treatment: A Meta-analysis of Comparison Group Studies.” Drug and Alcohol Dependence 67(1): 53-72.

Prendergast, Michael L., Elizabeth A. Hall, Harry K. Wexler, Gerald Melnick, and Yan Cao. 2004. “Amity Prison-based Therapeutic Community: 5-year Outcomes.” Prison Journal 84(1): 36-60.

Rajkumar, Andrew S., and Michael T. French. 1997. “Drug Abuse, Crime Costs, and the Economic Benefits of Treatment.” Journal of Quantitative Criminology 13(3): 291-322.

Reuter, Peter, and Alex Stevens. 2007. An Analysis of UK Drug Policy A Monograph Prepared for the UK Drug Policy Commission. London: UK Drug Policy Commission.

Rocheleau, Ann Marie, and David Boyum. 1994. Heroin Users in New York, Chicago, and San Diego. Washington, D.C.: White House Office of National Drug Control Policy.

Rossman, S.B., J. Zweig, and J. Roman. 2008. A Portrait of Adult Drug Courts. Washington, D.C.: Urban Institute. 
Sevigny, Eric L., and Jonathan P. Caulkins. 2004. "Kingpins or Mules: An Analysis of Drug Offenders Incarcerated in Federal and State Prisons.” Criminology and Public Policy 3(3): 40134.

Sindelar, Jody L., Mireia Jofre-Bonet, Michael T. French, and A. Thomas McLellan. 2004. “Cost-effectiveness Analysis of Addiction Treatment: Paradoxes of Multiple Outcomes.” Drug and Alcohol Dependence 73(1): 41-50.

Taxman, Faye S., Matthew L. Perdoni, and Lana D. Harrison. 2007. “Drug Treatment Services for Adult Offenders: The State of the State.” Journal of Substance Abuse Treatment 32(3): 23954.

UCLA Integrated Substance Abuse Programs. 2007. Evaluation of the Substance Abuse and Crime Prevention Act: Final Report. Los Angeles: UCLA Integrated Substance Abuse Programs.

Urada, Darren, Angela Hawken, Bradley T. Conner, Elizabeth Evans, M. Douglas Anglin, Joy Yang, Cheryl Teruya, Diane Herbeck, Jia Fan, Beth Rutkowski, Rachel Gonzales, Richard Rawson, Christine Grella, Michael Prendergast, Yih-Ing Hser, Jeremy Hunter, and Annie Poe. 2008. Evaluation of Proposition 36: The Substance Abuse and Crime Prevention Act of 2000, 2008 Report. Los Angeles: Department of Alcohol and Drug Programs California Health and Human Services Agency. 
Wilson, David B., Ojmarrh Mitchell, and Doris L. MacKenzie. 2006. “A Systematic Review of Drug Court Effects on Recidivism.” Journal of Experimental Criminology 2(4): 459-87.

Wish, Eric D., and Bernard A. Gropper. 1991. "Drug Testing by the Criminal Justice System.” In Crime and Justice: Drugs and Crime, (volume 13), edited by Michael J. Tonry and James Q. Wilson, 109-58. Chicago: University of Chicago Press. 
Table 1: Treatment Admissions for Cocaine, Heroin, Marijuana and Methamphetamine, TEDS 1997 and 2006

\begin{tabular}{lcccc}
\hline & $1997(N)$ & $1997(\%)$ & $2006(N)$ & $2006(\%)$ \\
\hline Cocaine & 236,770 & 15 & 250,135 & 14 \\
Heroin & 235,143 & 15 & 245,984 & 14 \\
Marijuana & 197,840 & 12 & 289,988 & 16 \\
Methamphetamine & 53,694 & 3 & 149,415 & 8 \\
\hline
\end{tabular}

Note: Each admission is classified according to primary drug of abuse but may involve polydrug abuse. Reported percentages are based on treatment admissions for all substances, including alcohol. 
Table 2: Eligibility Requirements for Four Major Drug Courts

\begin{tabular}{|c|c|c|c|}
\hline County & Program Type & Capacity & Eligibility \\
\hline \multirow[t]{3}{*}{ Dade county, FL } & Adult pretrial & 1,450 & No history of violent crime \\
\hline & & & No arrest for drug sale or trafficking \\
\hline & & & No more than two previous felony convictions \\
\hline \multirow[t]{3}{*}{ Brooklyn, NY } & Post-plea & NA & No prior felony conviction \\
\hline & & & No charges involving drug sale near school \\
\hline & & & No prior felony convictions \\
\hline \multirow[t]{5}{*}{ San Francisco, CA } & Pre-plea & 440 & No drug court failures in previous five years \\
\hline & & & No convictions for sales in previous eight \\
\hline & & & years \\
\hline & & & No current conviction for violent or serious \\
\hline & & & felony \\
\hline \multirow[t]{2}{*}{ Broward, FL } & Pretrial and post- & 2,649 & No prior felony or conviction \\
\hline & conviction & & No current sales/trafficking conviction \\
\hline
\end{tabular}


Table 3

\begin{tabular}{|l|l|l|}
\hline & HOPE & Control \\
\hline No-shows for probation appointments (average of appointments & $9 \%$ & $23 \%$ \\
\hline Positive urine tests (average of tests per probationer) & & \\
\hline New arrest rate (probationers rearrested) & $13 \%$ & $46 \%$ \\
\hline Revocation rate (probationers revoked) & $21 \%$ & $47 \%$ \\
\hline Incarceration (days sentenced) & $7 \%$ & $15 \%$ \\
\hline
\end{tabular}


Table 4: Sample Sizes and Reference Populations for the Four Inmate Surveys

\begin{tabular}{lrrrr}
\hline & \multicolumn{2}{c}{ Late 1980s } & \multicolumn{2}{c}{ Early 2000s } \\
\cline { 2 - 5 } & 1986 Prison & 1989 Jail & 2004 Prison & 2002 Jail \\
& Survey & Survey & Survey & Survey \\
\hline Stock Inmate Population & & & & \\
Sample $n$ & 13,711 & 5,675 & 14,499 & 6,982 \\
Population $N$ & 450,416 & 395,554 & $1,226,171$ & 631,241 \\
Newly Incarcerated Inmates & & & & \\
Sample $n$ & 5,270 & 2,656 & 5,033 & 4,582 \\
Population $N$ & 161,597 & 180,022 & 395,865 & 415,354 \\
\hline
\end{tabular}


Table 5: Percentage of Newly Incarcerated Convicted Inmates Reporting Daily or Near-Daily Substance Use, by Drug Type and Survey Year

\begin{tabular}{lcccc}
\cline { 2 - 4 } Drug Type $^{\mathrm{a}}$ & $\begin{array}{c}\text { 1986 State } \\
\text { Prison Inmates }\end{array}$ & $\begin{array}{c}\text { 1989 Local } \\
\text { Jail Inmates }\end{array}$ & $\begin{array}{c}\text { 2004 State } \\
\text { Prison Inmates }\end{array}$ & $\begin{array}{c}\text { 2002 Local } \\
\text { Jail Inmates }\end{array}$ \\
\hline Heroin & $7.5 \%$ & $5.1 \%$ & $5.3 \%$ & $4.5 \%$ \\
Cocaine & $13.7 \%$ & $13.7 \%$ & $13.4 \%$ & $12.0 \%$ \\
Methamphetamine & $5.1 \%$ & $2.8 \%$ & $11.8 \%$ & $7.7 \%$ \\
Any of the Three & $21.5 \%$ & $17.8 \%$ & $27.0 \%$ & $21.4 \%$ \\
\hline$N$ & 161,597 & 180,022 & 395,865 & 415,354 \\
\hline
\end{tabular}

\footnotetext{
${ }^{a}$ Percentage calculations are based on nonmissing data, the amount of which varies by indicator.
} 
Table 6: Drug Court Screening and Exclusion Criteria Among Newly-Incarcerated Convicted Inmates by Reported Abuse of Heroin, Cocaine, or Methamphetamine, 2002 Jail and 2004 Prison Surveys

\begin{tabular}{|c|c|c|c|c|}
\hline \multirow[b]{3}{*}{ Drug Court Criteria $^{\mathrm{a}}$} & \multicolumn{2}{|c|}{2002 Entering Jail Cohort } & \multicolumn{2}{|c|}{2004 Entering Prison Cohort } \\
\hline & \multicolumn{4}{|c|}{ Reported Daily or Near-Daily Use in Month Prior to Arrest } \\
\hline & Yes & No & Yes & No \\
\hline \multicolumn{5}{|l|}{ Screening/Eligibility Criteria } \\
\hline Current Drug Conviction & $48.2 \%$ & $26.5 \%$ & $46.6 \%$ & $29.8 \%$ \\
\hline Drug-Related Revocation ${ }^{\mathrm{b}}$ & $13.8 \%$ & $7.9 \%$ & $16.3 \%$ & $7.0 \%$ \\
\hline Positive Drug Test after Arrest ${ }^{\mathrm{c}}$ & $16.4 \%$ & $6.6 \%$ & $18.2 \%$ & $7.9 \%$ \\
\hline Screened for Drug Abuse ${ }^{\mathrm{d}}$ & $92.0 \%$ & $43.8 \%$ & $92.2 \%$ & $42.6 \%$ \\
\hline Screened for Drug Dependence ${ }^{\mathrm{e}}$ & $85.9 \%$ & $24.5 \%$ & $83.7 \%$ & $24.4 \%$ \\
\hline Met Any Screening/Eligibility Criteria & $97.1 \%$ & $58.5 \%$ & $97.7 \%$ & $60.4 \%$ \\
\hline \multicolumn{5}{|l|}{ Exclusion Criteria } \\
\hline Current Trafficking Conviction & $17.9 \%$ & $9.6 \%$ & $22.4 \%$ & $14.8 \%$ \\
\hline Current Violent Conviction & $17.2 \%$ & $28.1 \%$ & $17.2 \%$ & $30.7 \%$ \\
\hline Current Weapon Involvement ${ }^{\mathrm{f}}$ & $7.7 \%$ & $7.5 \%$ & $10.5 \%$ & $11.3 \%$ \\
\hline Habitual Offender Enhancement ${ }^{\mathrm{g}}$ & $5.4 \%$ & $6.3 \%$ & $16.2 \%$ & $13.2 \%$ \\
\hline Prior Incarceration Sentence & $77.2 \%$ & $60.6 \%$ & $62.5 \%$ & $46.3 \%$ \\
\hline Prior Violent Conviction & $27.8 \%$ & $27.6 \%$ & $27.4 \%$ & $23.8 \%$ \\
\hline Criminal Justice Status at Arrest ${ }^{\mathrm{h}}$ & $77.5 \%$ & $67.7 \%$ & $59.0 \%$ & $48.2 \%$ \\
\hline Current or Prior Violent Conviction & $32.6 \%$ & $39.1 \%$ & $36.6 \%$ & $45.1 \%$ \\
\hline Met Any Exclusion Criteria & $96.2 \%$ & $91.3 \%$ & $93.0 \%$ & $88.4 \%$ \\
\hline Mean Age in Years & 32.9 & 31.7 & 34.0 & 32.1 \\
\hline$N$ & 87,174 & 328,180 & 104,005 & 291,860 \\
\hline
\end{tabular}

${ }^{a}$ Percentage calculations are based on nonmissing data, the amount of which varies by indicator.

${ }^{\mathrm{b}}$ Revoked or facing revocation for a positive drug test, possessing drugs, or missing a drug test.

${ }^{\mathrm{c}}$ Received positive drug test at booking or shortly after admission to prison or jail

d Met the survey's criteria based on DSM for drug abuse in past year prior to arrest

e Met the survey's criteria based on DSM for drug dependence in past year prior to arrest

${ }^{\mathrm{f}}$ Revocation for possessing gun, receiving firearm sentence enhancement, having any current weapon conviction, or having gun seized by police at arrest.

${ }^{\mathrm{g}}$ Habitual offender enhancement is defined as receiving a sentence enhancement for a second- or third-strike offense

${ }^{\mathrm{h}}$ On probation, parole, or escape 
Table 7: Drug Court Screening and Exclusion Criteria Among All Convicted Inmates by Reported Abuse of Heroin, Cocaine, or Methamphetamine, 2002 Jail and 2004 Prison Surveys

\begin{tabular}{|c|c|c|c|c|}
\hline \multirow[b]{3}{*}{ Drug Court Criteria $^{a}$} & \multicolumn{2}{|c|}{2002 Jail Inmates } & \multicolumn{2}{|c|}{2004 Prison Inmates } \\
\hline & \multicolumn{4}{|c|}{ Reported Daily or Near-Daily Use in Month Prior to Arrest } \\
\hline & Yes & No & Yes & No \\
\hline \multicolumn{5}{|l|}{ Screening/Eligibility Criteria } \\
\hline Current Drug Conviction & $47.3 \%$ & $27.1 \%$ & $37.0 \%$ & $20.2 \%$ \\
\hline Drug-Related Revocation ${ }^{\mathrm{b}}$ & $13.6 \%$ & $7.6 \%$ & $11.2 \%$ & $4.6 \%$ \\
\hline Positive Drug Test after Arrest ${ }^{\mathrm{c}}$ & $16.4 \%$ & $6.9 \%$ & $22.9 \%$ & $10.8 \%$ \\
\hline Screened for Drug Abuse ${ }^{d}$ & $92.5 \%$ & $43.6 \%$ & $91.2 \%$ & $40.2 \%$ \\
\hline Screened for Drug Dependence ${ }^{e}$ & $85.9 \%$ & $24.5 \%$ & $83.1 \%$ & $22.1 \%$ \\
\hline Met Any Screening/Eligibility Criteria & $97.3 \%$ & $58.8 \%$ & $97.0 \%$ & $54.6 \%$ \\
\hline \multicolumn{5}{|l|}{ Exclusion Criteria } \\
\hline Current Trafficking Conviction & $18.0 \%$ & $10.4 \%$ & $19.5 \%$ & $11.1 \%$ \\
\hline Current Violent Conviction & $18.7 \%$ & $29.2 \%$ & $34.5 \%$ & $55.0 \%$ \\
\hline Current Weapon Involvement $\mathrm{f}^{\mathrm{f}}$ & $7.6 \%$ & $7.5 \%$ & $16.5 \%$ & $17.7 \%$ \\
\hline Habitual Offender Enhancement ${ }^{\mathrm{g}}$ & $5.7 \%$ & $6.7 \%$ & $24.8 \%$ & $17.4 \%$ \\
\hline Prior Incarceration Sentence & $77.0 \%$ & $60.2 \%$ & $65.4 \%$ & $46.8 \%$ \\
\hline Prior Violent Conviction & $28.3 \%$ & $27.8 \%$ & $31.4 \%$ & $25.7 \%$ \\
\hline Criminal Justice Status at Arrest ${ }^{\mathrm{h}}$ & $75.7 \%$ & $66.4 \%$ & $50.9 \%$ & $40.8 \%$ \\
\hline Current or Prior Violent Conviction & $33.5 \%$ & $40.1 \%$ & $51.8 \%$ & $64.7 \%$ \\
\hline Met Any Exclusion Criteria & $96.1 \%$ & $91.3 \%$ & $95.2 \%$ & $93.1 \%$ \\
\hline Mean Age in Years & 33.0 & 31.8 & 35.7 & 35.2 \\
\hline$N$ & 94,017 & 354,219 & 278,374 & 947,797 \\
\hline
\end{tabular}

${ }^{a}$ Percentage calculations are based on nonmissing data, the amount of which varies by indicator.

${ }^{\mathrm{b}}$ Revoked or facing revocation for a positive drug test, possessing drugs, or missing a drug test.

${ }^{c}$ Received positive drug test at booking or shortly after admission to prison or jail

${ }^{d}$ Met the survey's criteria based on DSM for drug abuse in past year prior to arrest

e Met the survey's criteria based on DSM for drug dependence in past year prior to arrest

${ }^{\mathrm{f}}$ Revocation for possessing gun, receiving firearm sentence enhancement, having any current weapon conviction, or having gun seized by police at arrest.

${ }^{\mathrm{g}}$ Habitual offender enhancement is defined as receiving a sentence enhancement for a second- or third-strike offense

${ }^{\mathrm{h}}$ On probation, parole, or escape 
Chapter 3: Harold Pollack et al.

Figure 1: Age Distribution of TEDS Cocaine Admissions, 1992 and 2006

Figure 2: Age Distribution of TEDS Heroin Admissions, 1992 and 2006

Figure 3: Number of Chronic Cocaine and Heroin Users (in thousands), 1988-2000

Source: What America’s Users Spend on Illicit Drugs 1988-2000

Figure 4: Arrestees Testing Positive for Various Drugs in the District of Columbia, 1984-2007

Source: Pretrial Services Agency

Figure 5: Drug Use among Arrestees Under Age 18, the District of Columbia, 1987-2007

Source: Pretrial Services Agency

Figure 6: Age Distributions of Newly-Incarcerated Inmates Reporting Cocaine Abuse

Figure 7: Age Distributions of Newly-Incarcerated Inmates Reporting Heroin Abuse

Figure 8: Age Distributions of Newly-Incarcerated Inmates Reporting Methamphetamine Abuse

Figure 9: Age Distributions of Newly-Incarcerated Inmates Reporting No Drug Abuse 
Figure 10: Violent and Habitual Offending by Age Group, Newly-Incarcerated Drug-Abusing Inmates, 2002/4 
Figure 1: Age Distribution of TEDS Cocaine Admissions, 1992 and 2006

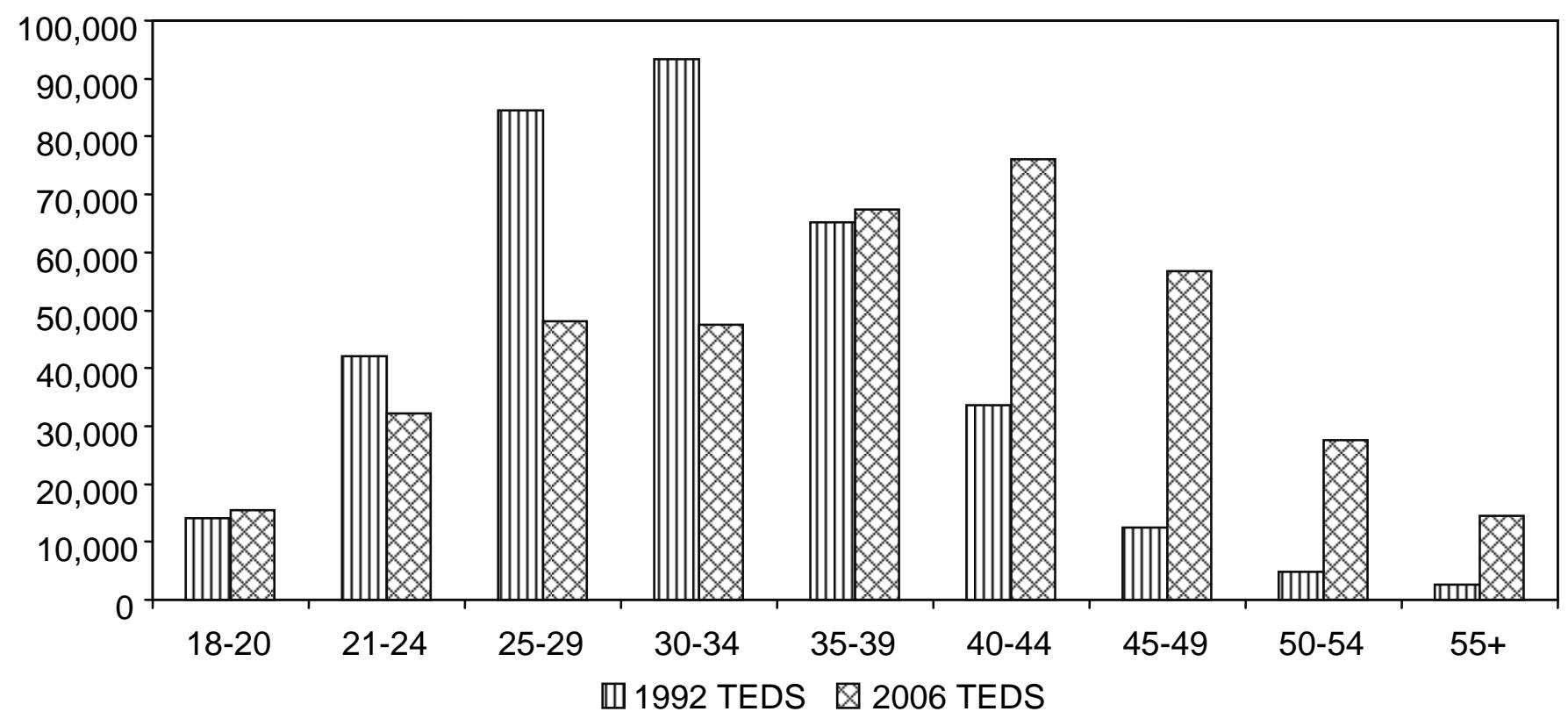


Figure 2: Age Distribution of TEDS Heroin Admissions, 1992 and 2006

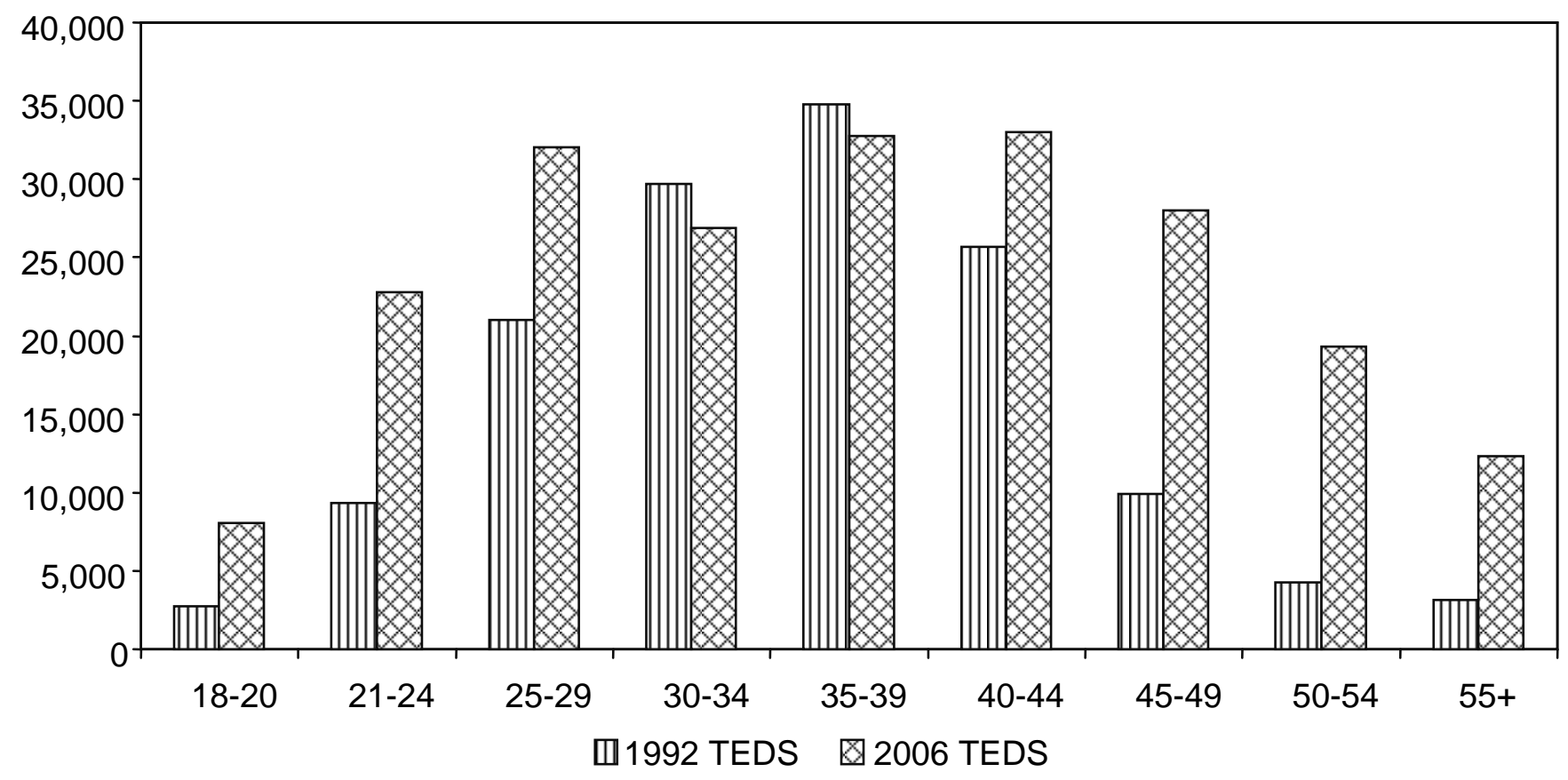


Figure 3: Number of Chronic Cocaine and Heroin Users (in thousands), 1988-2000

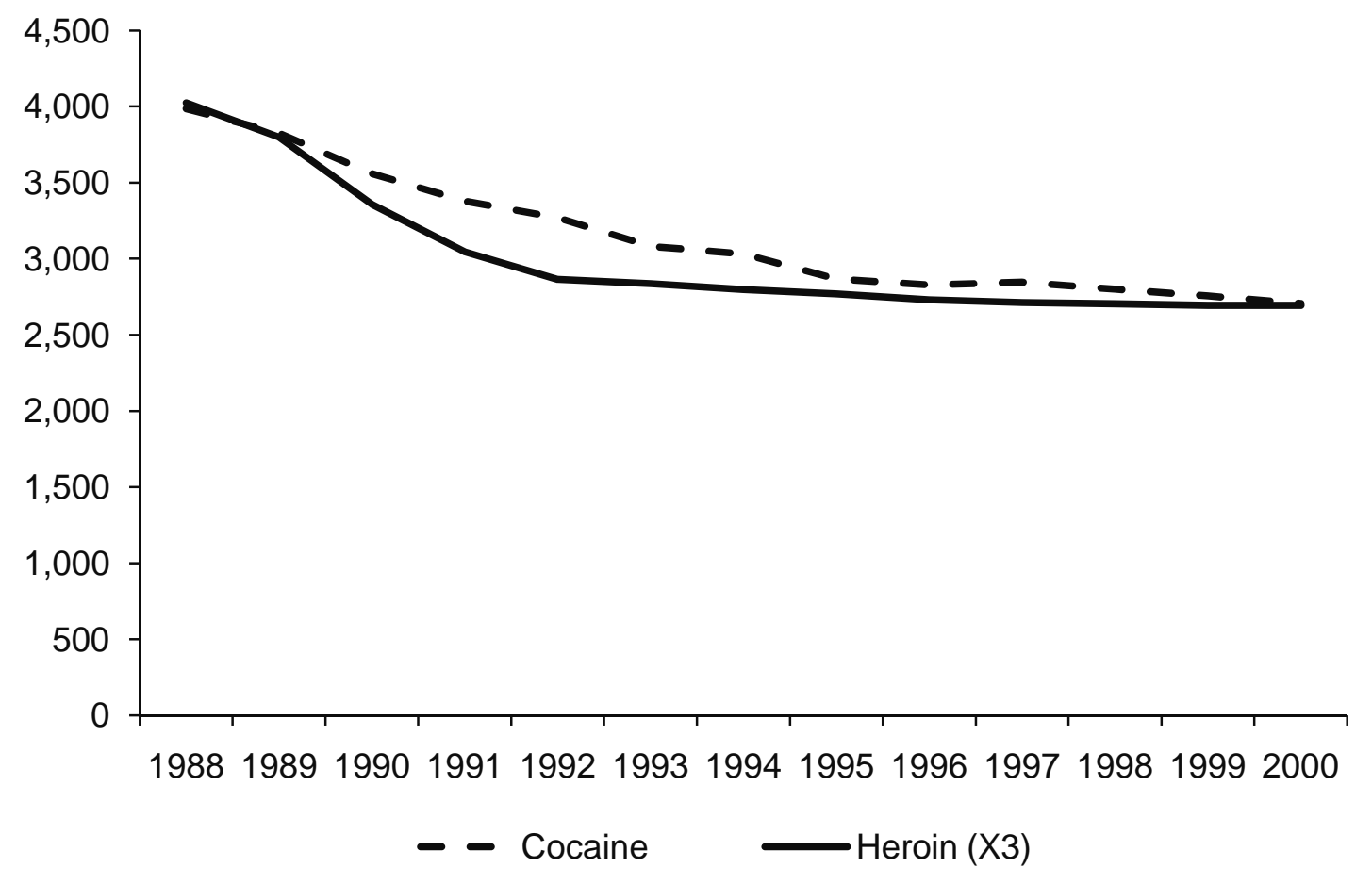

Source: What America's Users Spend on Illicit Drugs 1988-2000, ONDCP (2001) 
Figure 4: Arrestees Testing Positive for Various Drugs in the District of Columbia, 1984-2007

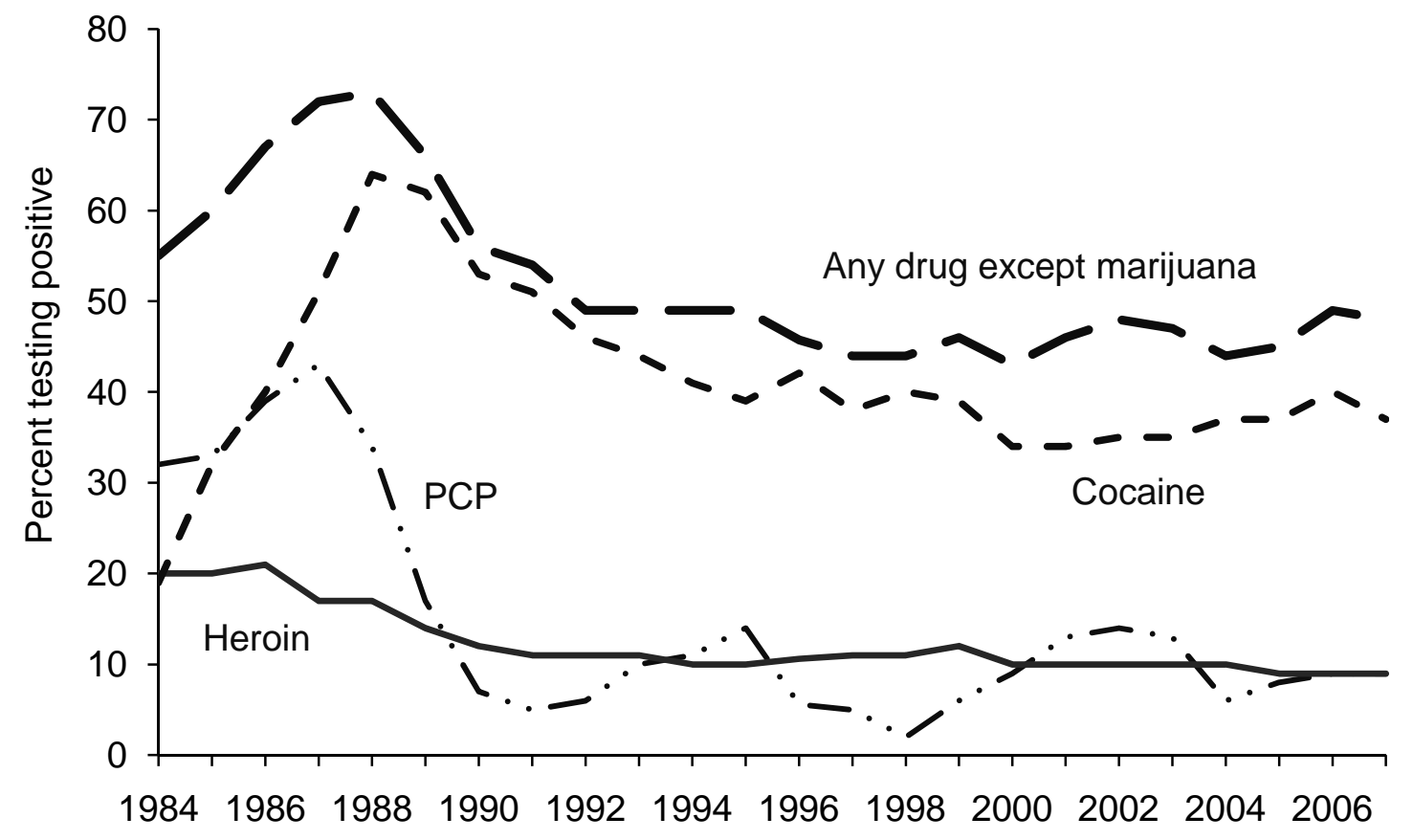

Source: Pretrial Services Agency 
Figure 5: Drug Use among Arrestees Under Age 18, the District of Columbia, 1987-2007

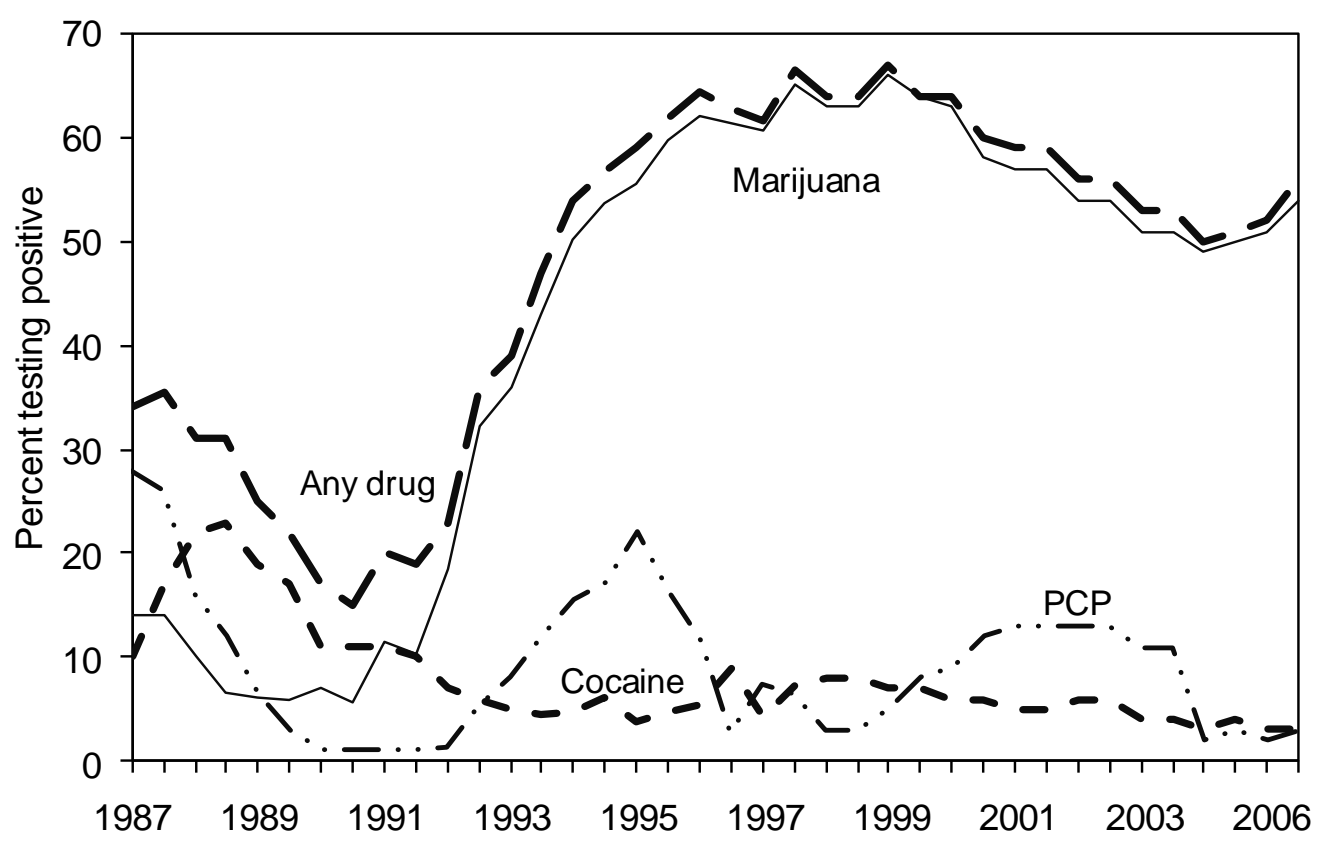

Source: Pretrial Services Agency 
Figure 6: Age Distributions of Newly-Incarcerated Inmates Reporting Cocaine Abuse

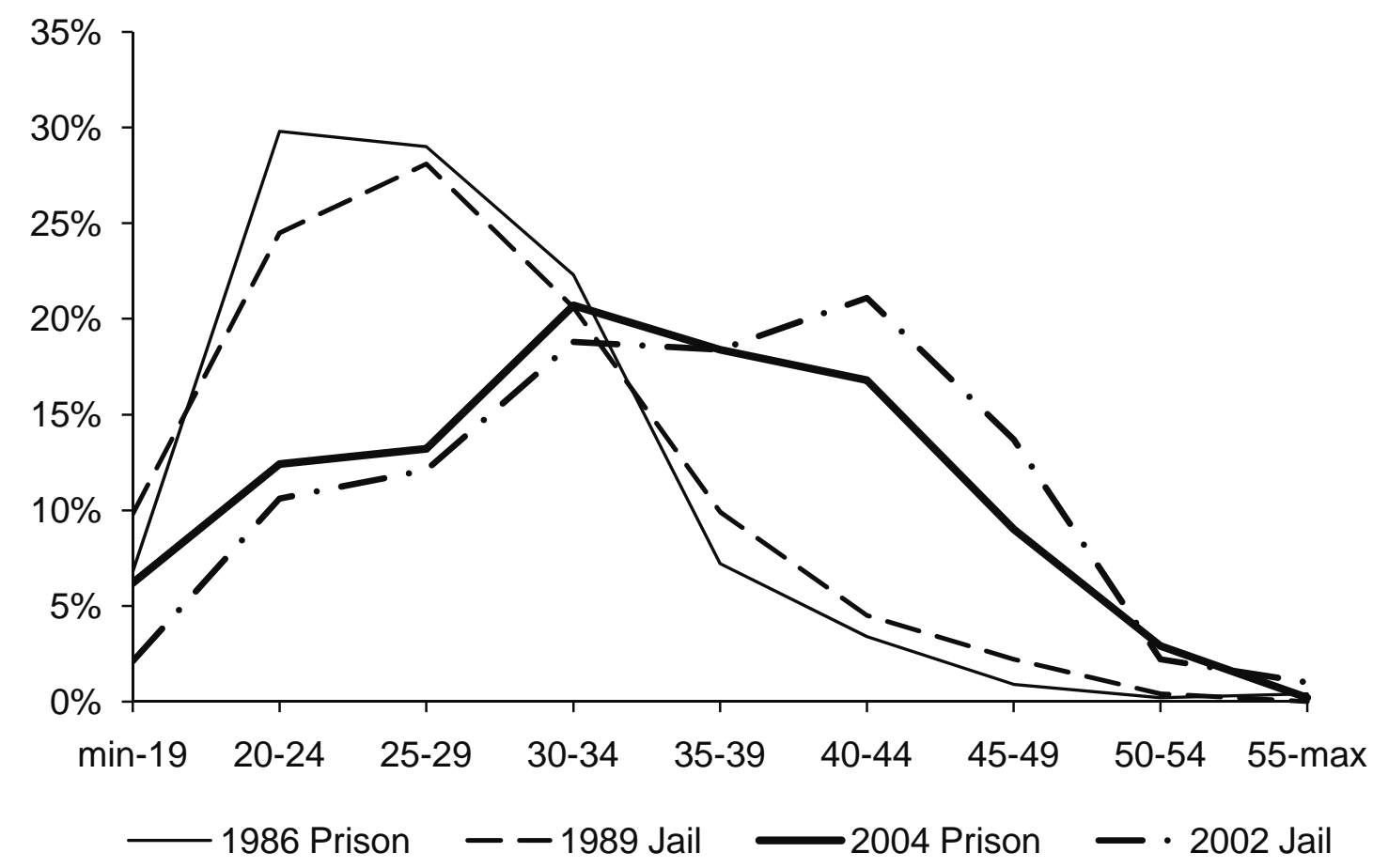


Figure 7: Age Distributions of Newly-Incarcerated Inmates Reporting Heroin Abuse

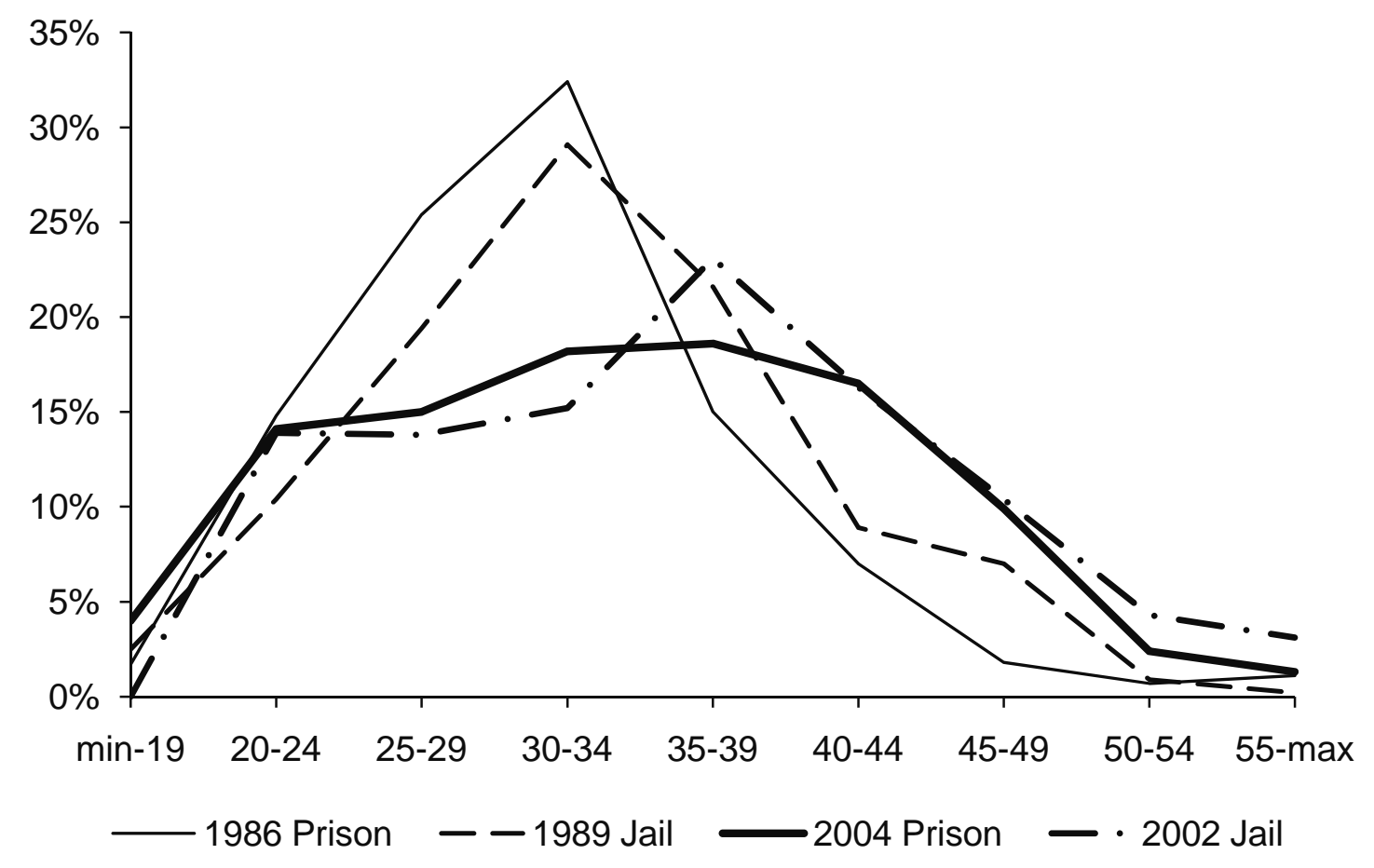


Figure 8: Age Distributions of Newly-Incarcerated Inmates Reporting Methamphetamine Abuse

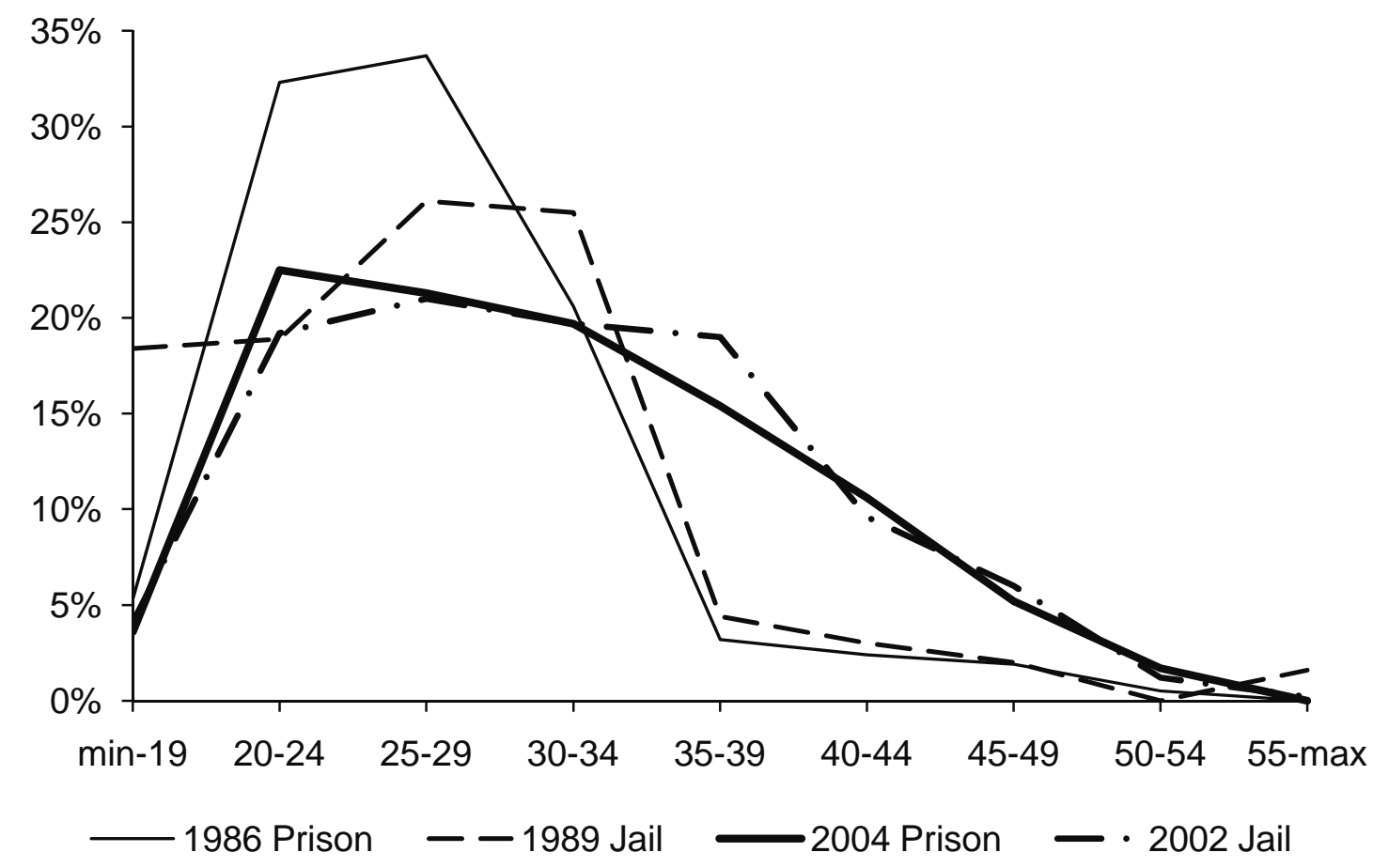


Figure 9: Age Distributions of Newly-Incarcerated Inmates Reporting No Drug Abuse

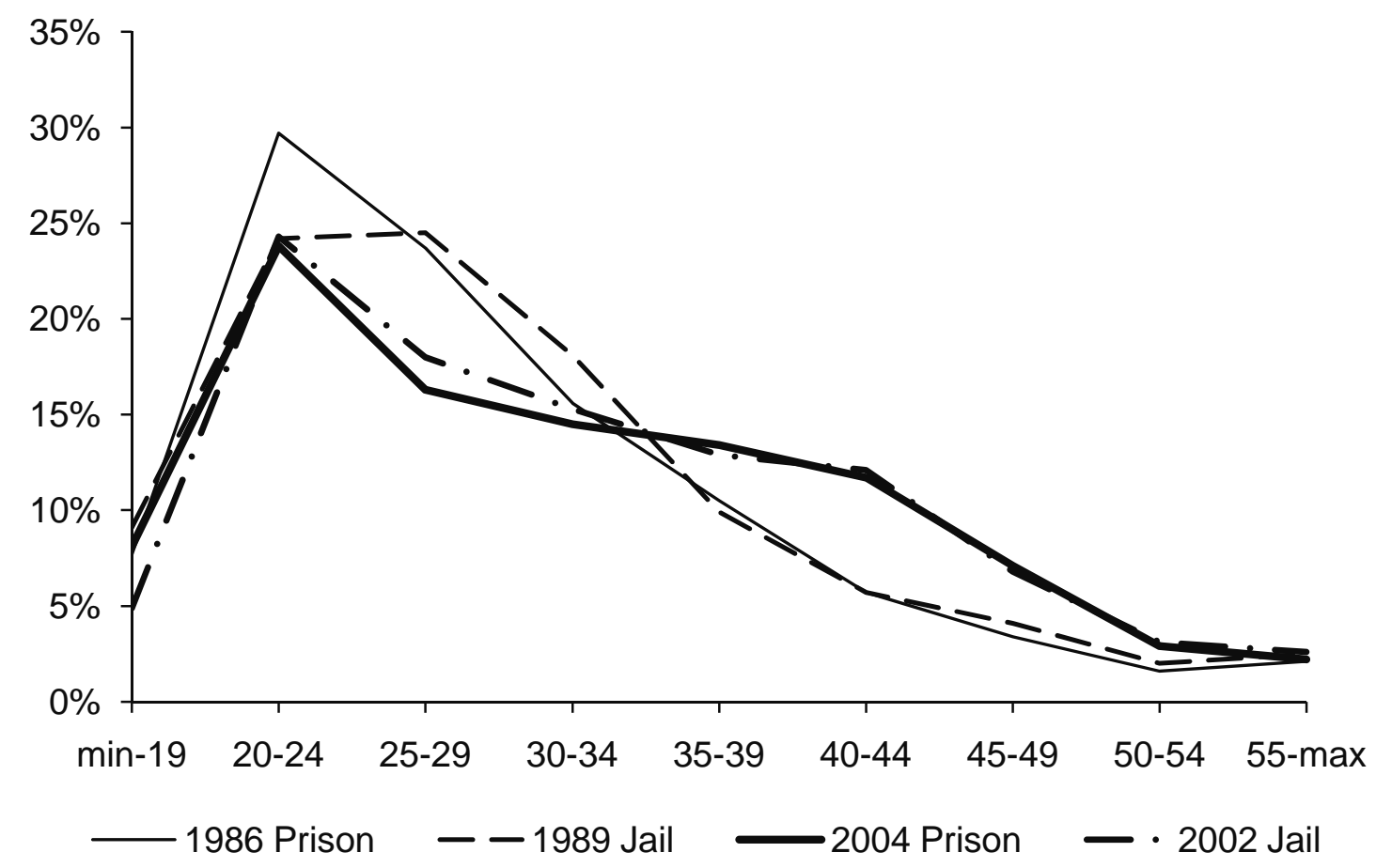


Figure 10: Violent and Habitual Offending by Age Group, Newly-Incarcerated Drug-Abusing Inmates, 2002/4

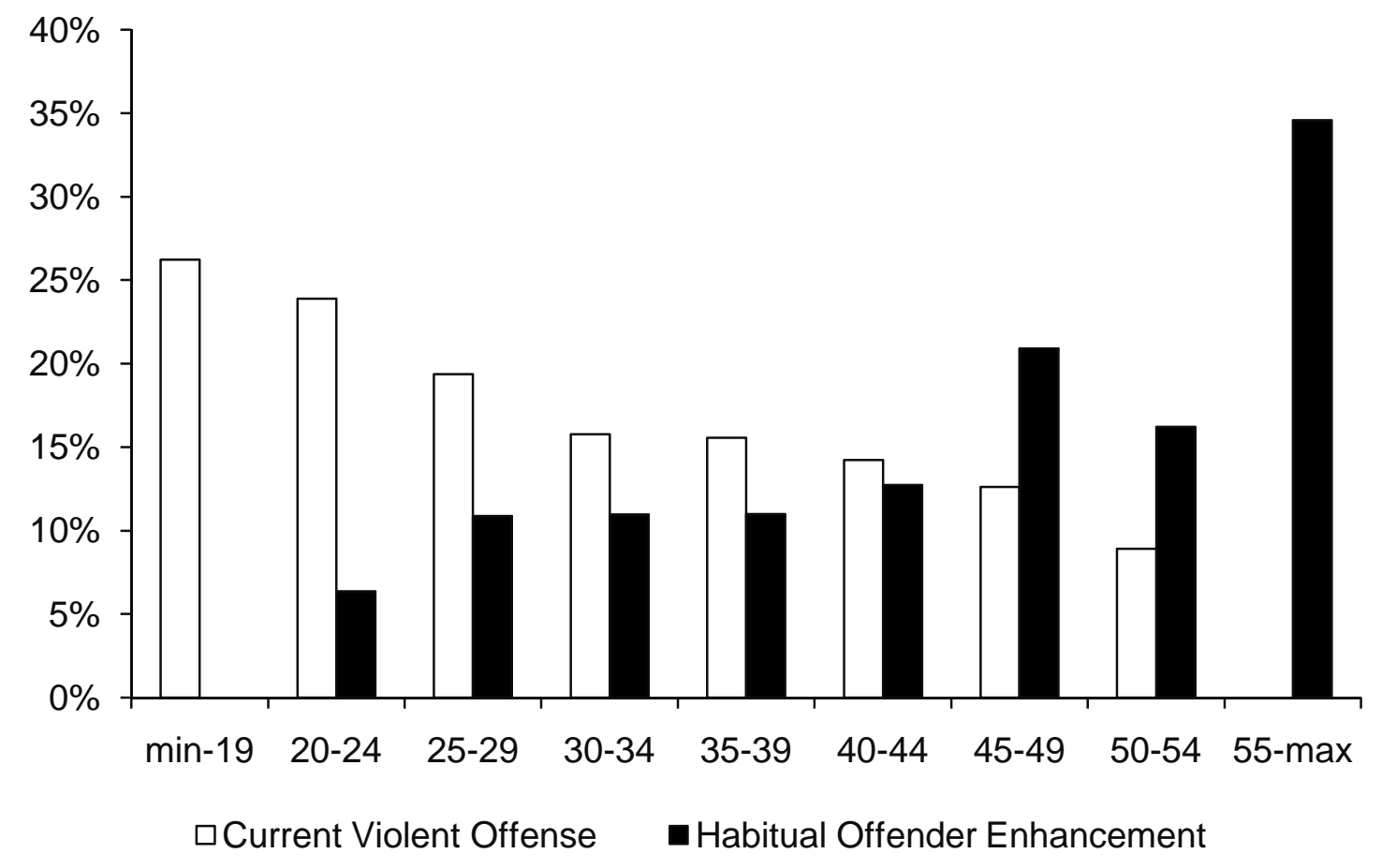

